\title{
Grazing, egg production, and biochemical evidence of differences in the life strategies of Calanus finmarchicus, C. glacialis and C. hyperboreus in Disko Bay, western Greenland
}

\author{
Rasmus Swalethorp ${ }^{1,2}$, Sanne Kjellerup ${ }^{1,2}$, Michael Dünweber ${ }^{1}$, \\ Torkel Gissel Nielsen ${ }^{1,2, *}$, Eva Friis Møller ${ }^{1}$, Søren Rysgaard ${ }^{3}$, \\ Benni Winding Hansen ${ }^{4}$ \\ ${ }^{1}$ Department of Marine Ecology, National Environmental Research Institute, University of Aarhus, Frederiksborgvej 399, \\ 4000 Roskilde, Denmark \\ ${ }^{2}$ National Institute of Aquatic Resources, DTU Aqua Section for Ocean Ecology and Climate, \\ Technical University of Denmark, Kavalergården 6, 2920 Charlottenlund, Denmark \\ ${ }^{3}$ Greenland Climate Research Centre, Greenland Institute of Natural Resources, PO Box 570, 3900 Nuuk, Greenland \\ ${ }^{4}$ Department of Environmental, Social and Spatial Change, Roskilde University, Universitetsvej 1, 4000 Roskilde, Denmark
}

\begin{abstract}
This is the first high temporal-resolution study in Disko Bay covering population dynamics, grazing, reproduction, and biochemical composition of 3 dominating copepod species (Calanus finmarchicus, C. glacialis and C. hyperboreus) from late winter to midsummer in 2008. C. finmarchicus and C. glacialis ascended to the surface layer at the onset of the spring phytoplankton bloom, followed by $C$. hyperboreus $2 \mathrm{wk}$ later. C. finmarchicus spawning occurred during the bloom and postbloom period, partially fueled by wax esters. C. glacialis commenced spawning before the bloom, yet it was greatly stimulated when food became available. However, feeding and reproduction was terminated after the main bloom despite the presence of food. In terms of feeding, this was also the strategy for C. hyperboreus. Between pre-bloom and post-bloom, C. finmarchicus showed an increase in carbon, nitrogen, and phospholipid content but a decrease in total lipid content. This was likely the result of protein synthesis, oocyte maturation, and spawning fueled by wax esters and by feeding. C. glacialis showed a similar pattern, although with an increasing total lipid content from pre-bloom to post-bloom, and an increasing wax ester and decreasing phospholipid content after reproduction was terminated. C. hyperboreus showed greatly increased content of carbon, nitrogen, and all lipid classes between the pre- and post-bloom periods. Hence, C. finmarchicus commenced feeding and spawning at the onset of the bloom and continued throughout the remaining study period. Both C. glacialis and C. hyperboreus females refueled their storage lipids (wax esters) during the bloom and post-bloom period, suggesting that they may spawn in an additional year.
\end{abstract}

KEY WORDS: Calanus spp. ' Distribution · Egg production ' Fecal pellet production · Carbon conversion factors · Lipids · Spring bloom

Resale or republication not permitted without written consent of the publisher

\section{INTRODUCTION}

The Arctic pelagic ecosystem is characterized by a short period of high primary production in the form of a spring phytoplankton bloom. The bloom is triggered by increased solar radiation into the water column fol- lowing the sea-ice breakup (Dünweber et al. 2010). This results in a meltwater injection and heating of the surface water that stratifies the water column and keeps the phytoplankton in the nutrient-rich photic layer. In Disko Bay, located on the west coast of Greenland, yearly to decadal variations in the extent of sea 
ice cover (Hansen et al. 2006) influences the timing of the diatom-dominated spring bloom (Heide-Jørgensen et al. 2007). Local ice melting and runoff from the glacier at Ilulissat creates a strong stratification and an outflow of low-saline water leaving the bay (Nielsen \& Hansen 1995, Buch 2000). Future increase in temperature will reduce the extent of the ice cover, promote stratification, and probably make the timing and duration of the bloom more predictable. However, wind is also an important factor in determining the onset of the bloom. Lack of sea ice can, in situations with prevailing winds, destabilize the water column and hence postpone the bloom (Melle \& Skjoldal 1998).

Copepods of the genus Calanus are the primary herbivores in Arctic pelagic ecosystems during spring and summer (Hirche \& Mumm 1992, Nielsen \& Hansen 1995, Thibault et al. 1999). Calanus spp. is an important prey item for many species of fish, birds, and whales (Dale \& Kaartvedt 2000, Kitaysky \& Golubova 2000, Laidre et al. 2007). C. finmarchicus is an Atlantic species, with a center of distribution in the Norwegian and Labrador Seas (Planque \& Batten 2000). C. glacialis is an Arctic shelf species present in the Barents Sea, Arctic Ocean, and several other marginal seas, while C. hyperboreus is an Arctic species centered around the Greenland Sea, Labrador Sea, and Arctic Ocean (Conover 1988, Hirche \& Mumm 1992, Hirche \& Kwasniewski 1997, reviewed by Falk-Petersen et al. 2009, and references therein). During late summer and early fall, the 3 Calanus species perform a downward vertical migration to a depth of 500 to $2000 \mathrm{~m}$, where they undergo diapause (reviewed by Lee et al. 2006, and references therein). Copepodite stages $\mathrm{V}, \mathrm{IV}$, and III (CV, CIV, and CIII respectively) are generally the first stages that can undergo diapause in C. finmarchicus, C. glacialis, and C. hyperboreus, respectively, and molting into adults occurs over one or more winters (reviewed by Falk-Petersen et al. 2007, and references therein). C. finmarchicus has a life cycle of $1 \mathrm{yr}$ and can have more $>1$ generation $\mathrm{yr}^{-1}, C$. glacialis has a life cycle of 1 to $3 \mathrm{yr}$, and that of $C$. hyperboreus is 1 to $6 \mathrm{yr}$ (reviewed by Falk-Petersen et al. 2009, and references therein). C. hyperboreus primarily spawn at depth during winter and early spring (Smith 1990, Hirche \& Niehoff 1996, Niehoff et al. 2002), while C. glacialis and $C$. finmarchicus spawn near the surface around the time of the spring bloom (Madsen et al. 2001, 2008b).

Spawning in Calanus hyperboreus occurs at depth, completely independent of food and only fueled by lipid storages (Lee 1974, Hirche \& Niehoff 1996). C. glacialis is also capable of reproducing based on its lipid deposits; however, egg production (EP) is greatly stimulated when food becomes abundant (Hirche \& Kattner 1993). The ability to reproduce in the absence of food is not as prominent in the smaller and less fat $C$. finmarchicus; an Arctic study found that this species depends on food being present to finalize oocyte maturation (Niehoff \& Hirche 1996), which was not the case in a North Atlantic study (Richardson et al. 1999). During the spring phytoplankton bloom and early summer, Calanus spp. develop from nauplii into the first copepodite stages capable of undergoing diapause, and lipid stores are filled, enabling them to survive and molt during the winter (Melle \& Skjoldal 1998, Madsen et al. 2001).

The 3 primary lipid classes found in Calanus spp. are triacylglycerol (TAG), wax esters (WE), and phospholipids. TAG is mainly a dietary lipid representing the immediate feeding history of the copepod, while WE is a storage lipid accumulated for winter diapause and used to fuel molting, gonad maturation, and early reproduction (Hakanson 1984, reviewed by Lee et al. 2006). Phospholipids are mainly structural lipids used in membranes (reviewed by Lee et al. 2006). These lipids are very important components in the energy transfer up through the Arctic marine food web (reviewed by Falk-Petersen et al. 1987, Saito \& Kotani 2000).

A seasonal study in Disko Bay (Madsen et al. 2001, Niehoff et al. 2002) has, as have other studies in the Arctic (e.g. Hirche \& Kwasniewski 1997, Melle \& Skjoldal 1998), shown the close coupling between the spring phytoplankton bloom and the distribution, development, feeding, and reproduction of the 3 dominating Calanus species. Available life-history models show eggs produced from lipid stores prior to the phytoplankton bloom to have the highest reproductive value and importance to population recruitment in high-latitude systems (Varpe et al. 2007), thus favoring species capable of spawning independent of food before the phytoplankton bloom (C. hyperboreus, and to a lesser extent $C$. glacialis). However, if the bloom occurs at a later time, the importance of lipid-fueled early-spawned eggs in recruitment decreases relative to later-spawned eggs fueled by feeding (Varpe et al. 2009), which may also be true if the bloom is prolonged (C. finmarchicus). However, simultaneous high-resolution measurements of distribution, grazing, body composition, and reproduction before, during, and after the phytoplankton bloom are needed to positively identify differences in strategies and life-cycle traits between these species.

The aim of the present study was to study the population development and life-history traits of 3 co-occurring Calanus species, C. finmarchicus, C. glacialis, and C. hyperboreus, with emphasis on the coupling to the spring phytoplankton bloom from late winter to mid-summer of 2008 in Disko Bay. Based on these life-history traits, we discuss expected challenges of the global-warming effects already in progress in Disko Bay. 


\section{MATERIALS AND METHODS}

Study site. Sampling was conducted from 21 February to 18 July 2008 in Disko Bay near Qeqertarsuaq, approximately 1 nautical mile off the coast. From February to 23 March, sampling was carried out from the ice $\left(69^{\circ} 14^{\prime} \mathrm{N}, 53^{\circ} 30^{\prime} \mathrm{W}\right)$, with a water depth of only 65 to $160 \mathrm{~m}$, because the ice cover was not stable at the deeper water monitoring station. Ship-based sampling was initiated on 9 April from RV 'Porsild' (Arctic Station, Copenhagen University) or the fishing boat 'Maya $\mathrm{S}^{\prime}$ at a monitoring station used in previous studies (Nielsen \& Hansen 1995, Madsen et al. 2001, 2008b, Niehoff et al. 2002) $\left(69^{\circ} 14^{\prime} \mathrm{N}, 53^{\circ} 23^{\prime} \mathrm{W}\right)$ at a depth of $300 \mathrm{~m}$ (Fig. 1). Sampling was carried out approximately once a week, with the exception of 2 gaps from 23 March to 9 April and 9 June to 12 July. Additionally, during an intensive period from 16 April to 4 May, sampling was conducted every 1 to $5 \mathrm{~d}$.

Hydrography. Salinity and temperature was measured throughout the study period with a Seabird CTD (SBE25-01). Measurements were conducted from the surface to a maximum depth of $156 \mathrm{~m}$ when sampling from the sea ice, and to a maximum depth of $278 \mathrm{~m}$ depth when sampling was ship-based.

Phytoplankton. Samples of 5 to 101 were taken using a 10 or 301 Niskin water bottle at 1, 20, 50, 75, 100,150 , and $250 \mathrm{~m}$ or down to the maximum possible depth when sampling at the shallower station. The water was kept in dark containers at $5^{\circ} \mathrm{C}$. On the first 9 sampling dates, the water froze and was thawed at $5^{\circ} \mathrm{C}$ for up to $18 \mathrm{~h}$. Later in the season, samples were processed within 4 to $10 \mathrm{~h}$ of sampling. Chlorophyll a (chl a) was measured by taking 3 subsamples of 100 to

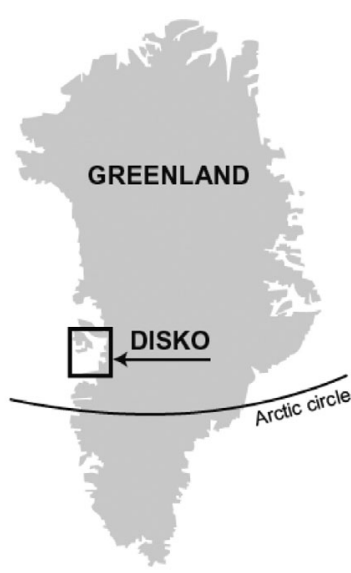

Fig. 1. Location of study sites

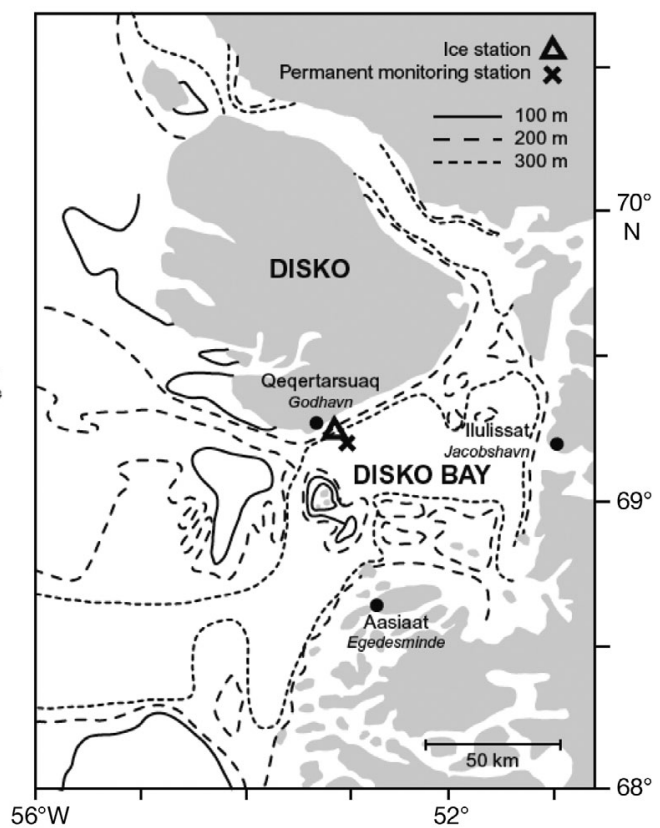

$500 \mathrm{ml}$, which were filtered onto GF/F filters, and at 1 , 20 , and $50 \mathrm{~m}$, subsamples were additionally filtered onto 10 and $50 \mu \mathrm{m}$ filters. Filters were extracted in $5 \mathrm{ml}$ $96 \%$ ethanol for $24 \mathrm{~h}$ (Jespersen \& Christoffersen 1987) and measured fluorometrically before and after $\mathrm{HCl}$ addition on a Turner fluorometer (TD-700) calibrated against a chl a standard. Chl a was converted to carbon using a chl a:particulate organic carbon (POC) ratio of 30 measured during a parallel investigation (Dünweber et al. 2010).

Calanus biomass. Copepods were sampled throughout the study at $50 \mathrm{~m}$ depth intervals from $250 \mathrm{~m}$ depth to the surface. During ice cover, sampling was carried out with a modified WP-2 net (45 $\mu \mathrm{m}$ mesh size) equipped with a closing mechanism and a nonfiltering cod-end, while from the vessels, a Hydrobios Multinet (Type Midi) equipped with a flowmeter was used with $250 \mathrm{~cm}$ long $50 \mu \mathrm{m}$ mesh-size nets. The nets were hauled with a speed of $0.5 \mathrm{~m} \mathrm{~s}^{-1}$. Samples were preserved in buffered formalin $(4 \%$ final concentration). Sampling was generally carried out at midday, except for one $24 \mathrm{~h}$ station between April 29 and 30 where samples were taken every $6 \mathrm{~h}$. Samples containing high numbers of copepods were split into subsamples. In each sample, stages CIII, CIV, and CV and adult males and females were distinguished by prosome length, which was measured for a maximum of 50 Calanus individuals per species in each sample, and additional Calanus spp. were counted (preferentially 300 specimens sample ${ }^{-1}$ ). Female biomass was estimated using regressions between prosome length and carbon content established in the present study to calculate population-specific fecal pellet production (FP) and egg production (EP) (see next section).

Calanus carbon and nitrogen content. From 23 March to 3 June, adult C. finmarchicus and C. glacialis were collected 9 times and $C$. hyperboreus females were collected 7 times for subsequent carbon and nitrogen content analysis in the upper $100 \mathrm{~m}$ following the same procedure as for the Calanus biomass. Collection was done using a WP-2 net (200 $\mu \mathrm{m}$ mesh size) equipped with a closing mechanism and a non-filtering cod-end, or a Multinet with $300 \mu \mathrm{m}$ mesh-size nets. After sampling, copepods were quickly transferred into buckets placed submerged in thermo boxes filled with ice and seawater. Within 3 to $5 \mathrm{~h}$ of collection, adult females were sorted in Petri dishes kept in ice-filled trays under a dissecting microscope. Between 10 and 20 females of each species were length-measured (prosome length), washed in GF/F filtered seawater, and placed individually in 
tin capsules. Females were then dried at $60^{\circ} \mathrm{C}$ for $24 \mathrm{~h}$, weighed, and stored at $-30^{\circ} \mathrm{C}$. Within 6 to $8 \mathrm{mo}$, carbon and nitrogen was measured on a CHNS Automatic Elemental Analyzer (EA 1110, CE Instruments).

Carbon content was measured in fecal pellets produced by Calanus finmarchicus on diets of culture algae Thalassiosira weissflogii and Rhodomonas salina in excess concentrations (ca. $400 \mu \mathrm{g} \mathrm{Cl}^{-1}$ ), respectively, and the carbon and nitrogen content was measured in eggs produced by C. finmarchicus and C. glacialis. Duplicate series of 20,40,60, and 80 eggs and fecal pellets were collected individually by micropipette on pre-combusted GF/F filters. For eggs, an additional series of 2 times 100 eggs was performed. Between 10 and 100 females were transferred from the ad libitum fed stock cultures and placed in a bucket filled with 21 of $0.2 \mu \mathrm{m}$-filtered seawater containing a cylinder with a false bottom (400 $\mu \mathrm{m}$ mesh size) to separate the females from the produced eggs and fecal pellets. The females were allowed to defecate for approximately $1 \mathrm{~h}$. The cylinder with the females was removed and the pellets were concentrated on a $40 \mu \mathrm{m}$ sieve. The fecal pellets and eggs were rinsed into a Petri dish placed in ice. Within $30 \mathrm{~min}$, they were transferred by micropipettes to pre-combusted GF/F filters. The filters containing pellets or eggs were dried at $60^{\circ} \mathrm{C}$ for $24 \mathrm{~h}$ and packed into tin capsules (Ultra clean) and the total organic carbon and nitrogen content determined on a CN elemental analyzer (Sercon-GSL) in line with a mass spectrometer (Sercon CF 20-20). The carbon and nitrogen content in the samples was calculated from an analysis of Certified Organic Analytical Standards (Sercon). A subsample of the collected pellets was taken for measuring the individual length and maximum width. The shape of each pellet resembles a rod with gradually tapered ends. Fecal pellet volume was therefore estimated as the average of a cylinder with 2 conjoined cones. The size of the egg was assumed to be the same as those collected in the field using a mean egg volume for each species (Table 1).

Prosome length to carbon weight regressions were generated for Calanus finmarchicus and C. glacialis combined, and for C. hyperboreus separately. Regressions were divided into a pre- and early bloom (up to and including April 30) and a late- and post-bloom period. The split was defined by the temporal center of the phytoplankton bloom where female Calanus spp. showed a significant increase in carbon content (see 'Results'). Furthermore, a single fecal pellet volume to carbon weight linear regression was generated for both types of food combined, as was an egg volume to carbon weight linear regression for $C$. finmarchicus and C. glacialis combined.

Calanus lipid content. Adult females of all 3 species were collected and sorted following the same procedure as for females collected for carbon measurements. The females were washed in GF/F filtered seawater and placed in a lipid test tube with a Teflon cap filled with $2 \mathrm{ml}$ of chloroform (HPLC grade). Then 4 to 5 C. finmarchicus, 2 to 3 C. glacialis, or 1 C. hyperboreus were added to each glass, in 6 to 10 replicates for each date. The samples were stored at $-30^{\circ} \mathrm{C}$ for 1 to $4 \mathrm{mo}$ and thereafter at $-80^{\circ} \mathrm{C}$ for 7 to 8 mo. Samples were homogenized by ultrasound and lipids extracted in $3 \mathrm{ml}$ chloroform:methanol (2:1 vol.) for $24 \mathrm{~h}$ at $-20^{\circ} \mathrm{C}$ as described by Folch et al. (1957). Samples were purified by mixing with $0.75 \mathrm{ml} 0.88 \% \mathrm{KCl}$ in a water solution and removing the lower lipid-containing phase as described by Madsen (2005). The solvent was evaporated under nitrogen gas at $55^{\circ} \mathrm{C}$, lipids were re-dissolved in $0.9 \mathrm{ml}$ chloroform, and non-polar and polar lipid classes separated on an $\mathrm{NH}_{2}$-SPE column conditioned with $n$-hexane. Non-polar lipids were eluted with $2 \mathrm{ml}$ chloroform:2-propanol (2:1 vol.) and polar lipids with $2 \mathrm{ml}$ acetic acid (6\%) in methanol. The nonpolar lipid fraction containing WE and TAG was evaporated under nitrogen gas at room temperature, redissolved in $1 \mathrm{ml} 0.5 \%$ tetrahydrofurane (THF) in $n$-hexane, and analyzed on a Dionex HPLC system (Dionex P680 pump and a Dionex Gina 50 auto sampler) with an Alltech MKIII Evaporative Light-Scattering Detector using Chromeleon (v. 6.80) software as described by Madsen et al. (2008a). Linoleyl linoleate and fish oil were used as standards for WE and TAG, respectively, and the calibration curves were generated as a second-degree polynomial function (Madsen et al. 2008a). The polar fraction of phospholipids was evaporated with nitrogen gas at $30^{\circ} \mathrm{C}$ and broken down to $\mathrm{P}_{\mathrm{i}}$ by adding $1 \mathrm{ml}$ of perchloric acid (70\%) and heated at $150^{\circ} \mathrm{C}$ (Zhou \& Arthur 1992) for $30 \mathrm{~min}$. A part of the sample $(0.25 \mathrm{ml})$ was dissolved in $0.75 \mathrm{ml}$ $\mathrm{H}_{2} \mathrm{O}$ and $5 \mathrm{ml}$ malachite solution $(0.2 \%)$, mixed, and

Table 1. Calanus finmarchicus and C. glacialis egg measurements. Egg carbon content is calculated using the volume to carbon regressions in Fig. 5. For egg carbon and egg nitrogen content, $n=15$. Data are mean $\pm S D$

\begin{tabular}{|lccccc|}
\hline Species & $\mathrm{n}$ & $\begin{array}{c}\text { Egg diameter } \\
(\mu \mathrm{m})\end{array}$ & $\begin{array}{c}\text { Egg volume } \\
\left(\times 10^{5} \mu \mathrm{m}^{3}\right)\end{array}$ & $\begin{array}{c}\text { Egg carbon content } \\
\left(\mu \mathrm{egg}^{-1}\right)\end{array}$ & $\begin{array}{c}\text { Egg nitrogen content } \\
\left.(\mu \mathrm{g} \mathrm{egg})^{-1}\right)\end{array}$ \\
\hline C. finmarchicus & 1775 & $153 \pm 10$ & $19.0 \pm 4.0$ & $0.21 \pm 0.04$ & $0.06 \pm 0.01$ \\
C. glacialis & 2883 & $178 \pm 12$ & $30.0 \pm 5.7$ & $0.33 \pm 0.06$ & $0.10 \pm 0.02$ \\
\hline
\end{tabular}


measured spectrophotometrically at $660 \mathrm{~nm}$ after 20 min (Madsen et al. 2008a). Standards of potassium dihydrogen phosphate $\left(\mathrm{KH}_{2} \mathrm{PO}_{4}\right)$ were converted into phospholipids using a $\mathrm{KH}_{2} \mathrm{PO}_{4}$ :diheptadecanoyl phosphatidylcholine conversion factor of 5.6 as reported by Madsen (2005).

Calanus spp. egg and fecal pellet production. Approximately once a week outside the main phytoplankton bloom and every 1 to $5 \mathrm{~d}$ during the bloom, live adult females of C. finmarchicus and C. glacialis were collected in the upper $100 \mathrm{~m}$ to determine their EP and FP rates. Females of $C$. hyperboreus were also collected from 25 April to determine their FP production. Females were sampled using a $200 \mu \mathrm{m}$ mesh size WP-2 net with a non-filtering cod-end. Live copepods were handled and females sorted following the same procedure as for females collected for carbon measurements. Within 2 to $4 \mathrm{~h}$ of collection, 15 to 20 C. finmarchicus, 15 to 20 C. glacialis, and 10 C. hyperboreus were incubated individually in $600 \mathrm{ml}$ polycarbonate bottles. The bottles were filled with $45 \mu \mathrm{m}$ screened seawater collected from $20 \mathrm{~m}$ water depth and incubated in thermo boxes filled with ice and water. The temperature was adjusted during the season to follow the in situ conditions. C. finmarchicus and C. glacialis were incubated for approximately $48 \mathrm{~h}$ and C. hyperboreus for $24 \mathrm{~h}$. After incubation, the bottles were filtered onto a $45 \mu \mathrm{m}$ filter, prosome length of the females were measured, while eggs and pellets were measured and counted immediately after incubation or preserved in acid Lugol's (2\% final concentration) for later measurement. Eggs and pellets were measured at $40 \times$ magnification using a dissecting microscope. Egg and pellet width was determined to the nearest $8 \mu \mathrm{m}$ and pellet length to the nearest $25 \mu \mathrm{m}$. Pellets were only considered for study if the length was minimum 3 times the width. During and after the phytoplankton bloom, 30 eggs and 30 pellets were measured in half of the bottles. Additional eggs and pellets were counted, and in the remaining bottles, all eggs and pellets were counted assuming equal size.

Specific egg production (SEP: $\mu g \mathrm{C}_{\text {egg }}\left(\mu \mathrm{g} \mathrm{C}\right.$ female) ${ }^{-1}$ $\mathrm{d}^{-1}$ in \%) was calculated using number of eggs, a mean egg volume for the entire period (Table 1), and the egg volume to carbon conversion factor (see Fig. 5b). Specific fecal pellet production (SPP: $\mu \mathrm{g} \mathrm{C}_{\text {fecal pellet }}(\mu \mathrm{g} \mathrm{C}$ female $)^{-1} d^{-1}$ in \%) was calculated using number of pellets, the mean pellet volume for pellets produced at each date, and the pellet volume to carbon conversion factor (see Fig. 5a). Female carbon content was calculated using length to carbon equations (see Fig. 4). The pre- and early bloom length-to-carbon conversion factors were applied to females measured up to and including 4 May, while the late- and post-bloom factor was applied to females measured after 4 May.
Carbon budgets. Biomass increase in percentage by the 3 Calanus species was calculated for the bloom period (16 April to 19 May) as the difference in mean female carbon weight between the pre-bloom (27 February to 16 April) and the post-bloom period (19 May to 18 July). It was thus assumed that sampling was carried out on one meta-population and others were not advected in, and that no size differential migration or mortality occurred during the study. SEP and SPP in percentage (carbon) was calculated for each species in the 3 respective periods by integrating the SEP and SPP rates in each period. The EP and FP production in carbon for the female population was then calculated by multiplying the integrated female carbon biomass in the upper $50 \mathrm{~m}$ of the water column in each period with the corresponding integrated SEP and SPP rate. This was done for each of the 3 Calanus species and it was assumed that all females within the upper $50 \mathrm{~m}$ had a productivity equivalent to females incubated in water taken from $20 \mathrm{~m}$.

Data analysis. Tests of copepod differences between bloom periods, specific dates, or species with respect to spawning, EP, FP, carbon, and total lipid content were conducted using a nonparametric Mann-Whitney $U$ test when comparing 2 groups and a Kruskal-Wallis test followed by a multiple range test when comparing 3 groups. The level of significance of correlations for female carbon weight versus prosome length (ln-transformed data), female carbon weight versus dry weight, fecal pellet carbon weight versus fecal pellet volume, egg carbon weight versus egg volume linear regressions, and SPP versus chl a hyperbolic regression was determined using ANOVA. Slopes and intercepts of female carbon to prosome length regressions (ln-transformed data) for the pre- and early bloom compared to the late and post-bloom were tested using multiple regression analysis. Slopes for female carbon versus dry weight regressions for the 3 species were compared using a $t$-test.

\section{RESULTS}

\section{Hydrography and chl a}

During the winter, Disko Bay was covered by sea ice from early January to early April and drifting sea ice was present off Qeqertarsuaq until late April. The temperature in the upper $50 \mathrm{~m}$ was relatively homogeneous $\left(<-1.3^{\circ} \mathrm{C}\right)$ until early April, and the chl a concentration was $<0.1 \mu \mathrm{g} \mathrm{l}^{-1}$ (Fig. 2). Around 9 April, an upwelling of warmer high-saline water stratified the water column, creating a surface mixed layer down to $50 \mathrm{~m}$, which triggered the phytoplankton bloom. The pycnocline was further strengthened by freshening of the surface water 


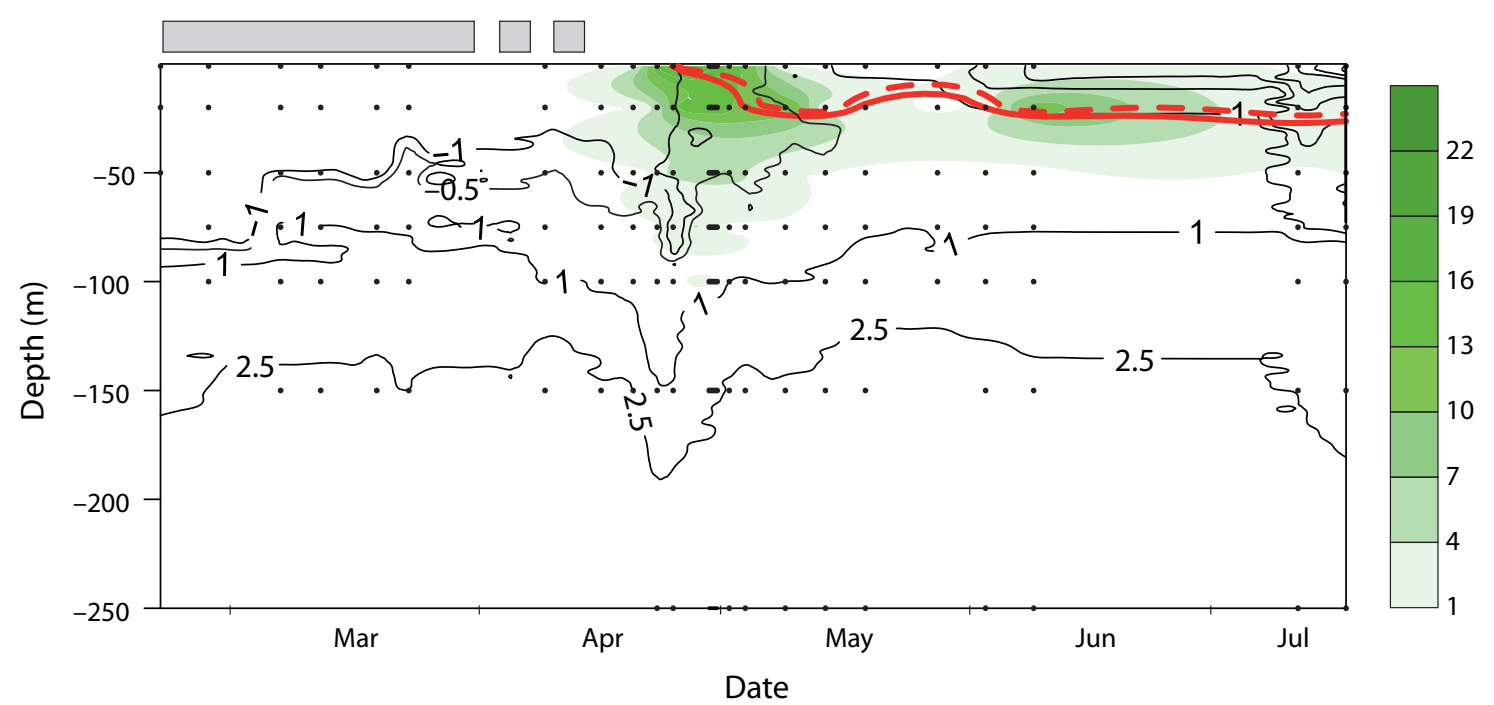

Fig. 2. Water temperature (isolines) in ${ }^{\circ} \mathrm{C}$, concentration of $\mathrm{chl}$ a (green area) in $\mu \mathrm{g} \mathrm{l^{-1 }}$ (right scale), and nitrate concentration at $0.5 \mu \mathrm{M}$ (dashed red line) and $1.0 \mu \mathrm{M}$ (solid red line) throughout the study period. Grey bar illustrates sea ice cover. Black dots represent date and depth of sampling

around 23 April (data not shown; see Dünweber et al. 2010 for additional information). From 16 April to 25 April, surface chl a concentration increased exponentially from 0.8 to $24 \mathrm{\mu g} \mathrm{l}^{-1}$, after which the bloom gradually settled due to depletion of nitrate in the euphotic zone and reaching a chl a concentration of $1.2 \mu \mathrm{g} \mathrm{l}^{-1}$ on 9 May. On 19 May, meltwater reduced the depth of the mixed layer to $10 \mathrm{~m}$, and a subsurface bloom was observed in early June at $20 \mathrm{~m}$, with the chl a concentration reaching $12 \mathrm{\mu g} \mathrm{l}^{-1}$. At the next measurement on 12 July, the subsurface bloom had ended.

\section{Calanus community structure and distribution}

The abundance of the 3 Calanus species was low in the upper $150 \mathrm{~m}$ of the water column until mid-March (Fig. 3a-i). C. finmarchicus and C. glacialis increased in abundance from mid-March, possibly migrating from the deeper trenches in Disko Bay. Their abundance peaked around mid-April at the onset of the spring phytoplankton bloom, while the abundance of C. hyperboreus increased from mid-April and peaked in early May. After mid-May, C. finmarchicus and C. glacialis were only present in the upper $50 \mathrm{~m}$, with decreasing abundance from early June, while C. hyperboreus remained abundant throughout the study period, also at the deeper depth strata. At 150 to $250 \mathrm{~m}$, the 2 smaller Calanus species had very low abundances compared to the larger $C$. hyperboreus (Fig. 3j-o). Samples were not collected below $150 \mathrm{~m}$ before 9 April. However, at the time where C. finmarchicus and C. glacialis abundances peaked in the up- per $150 \mathrm{~m}$, the abundance was very low in the deeper water layers (Fig. 3j,k,m,n). There was also a temporal transition in the top $150 \mathrm{~m}$, moving from lower depth strata to the surface, but no evidence of downward migration towards the end of the study. C. hyperboreus displayed a clear upward migration, moving through all depth strata from late April to early May (Fig. 3c,f,i, $1,0)$. Afterwards, the abundance remained low at 100 to $250 \mathrm{~m}$ until mid-May. Between 23 April and 2 May, the abundance decreased significantly in the top $50 \mathrm{~m}$, while it increased from 50 to $100 \mathrm{~m}$ for all 3 species (Fig. 3a-f). Integrated abundances in the top $100 \mathrm{~m}$ showed a reduction around this period for C. finmarchicus and C. glacialis but not as pronounced as indicated in the top $50 \mathrm{~m}$, confirming that a large proportion of the decrease in abundance could be explained by downward migration by especially $C$. glacialis and C. hyperboreus. The narrow peak at 0 to $50 \mathrm{~m}$ in the middle of this period represents samples taken at 18:00 h, midnight, and 06:00 h on 30 April (samples generally taken at midday), which corresponds to a drop in the 50 to $100 \mathrm{~m}$ strata that could indicate a considerable diurnal migration.

Stage CV individuals and adult females dominated the Calanus finmarchicus and C. glacialis populations at all depth strata. At the beginning of the study, CV constituted the majority of the populations, which shifted towards adult females dominating in mid-April. At this point CIII were also present in the top $50 \mathrm{~m}$ and CIV in the top $100 \mathrm{~m}$ and they contributed substantially to the copepodite populations. After 1 May, adult females were the dominating stage for $C$. finmarchicus, while CV still made up a considerable proportion of the 
C. finmarchicus
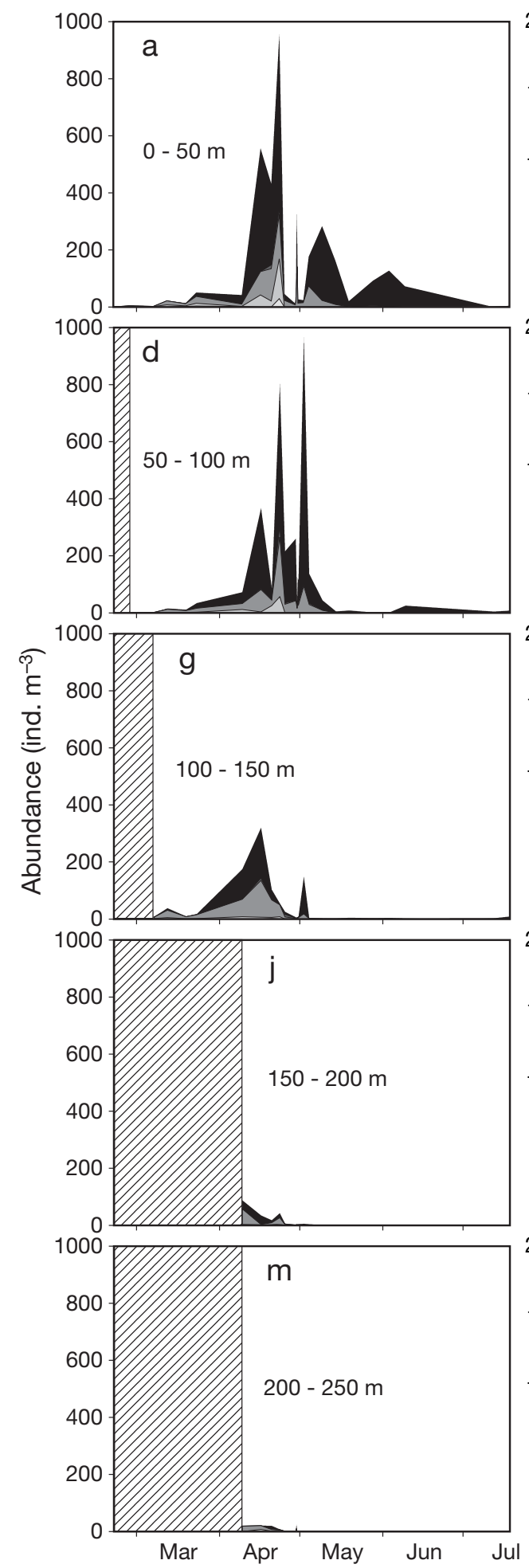

C. glacialis
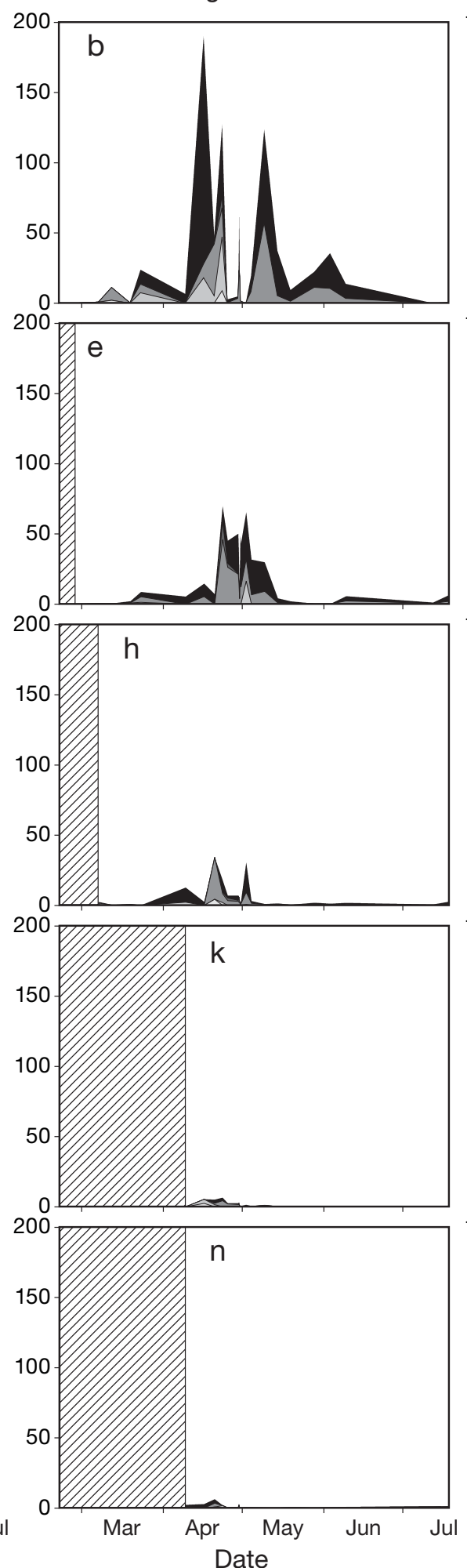

C. hyperboreus
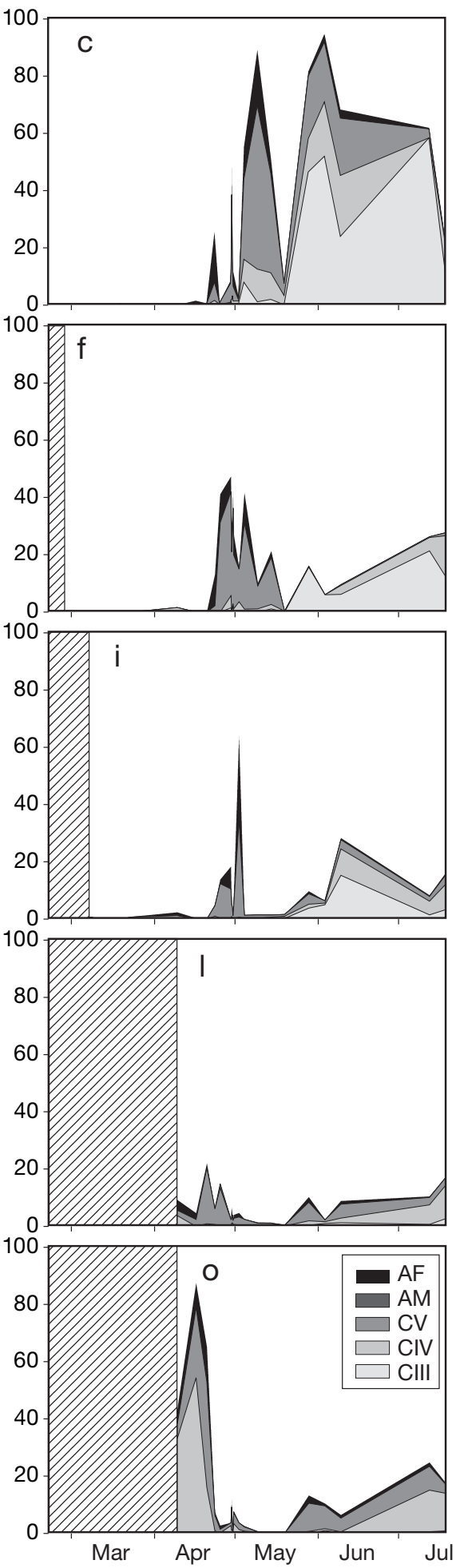

Fig. 3. Calanus finmarchicus, C. glacialis, and C. hyperboreus. Abundance of copepodite stages III (CIII), IV (CIV), V (CV), adult males (AM), and adult females (AF) at depth intervals (a-c) 0-50 m, (d-f) 50-100 m, (g-i) 100-150 m, (j-l) 150-200 m, and (m-o) 200-250 m. Note that sampling began on 21 February, while at 50-100, 100-150, and $150-250 \mathrm{~m}$, sampling was not initiated before 27 February, 7 March, and 9 April, respectively (hatched area). Note the diurnal migration in the upper layers between 25 April and 2 May and the different scales on the $y$-axes 
C. glacialis population (Fig. 3a,b,d,e). Adult males of $C$. finmarchicus and C. glacialis were present mainly during the bloom below $50 \mathrm{~m}$ but in low abundances. During late April at 200 to $250 \mathrm{~m}$, the C. hyperboreus population was mainly CIV and to a smaller extent CV and adult females, which following the upward migration, transformed into a CV-dominated population in the upper depth strata (Fig. 3c,f,i,l,o). Around mid-May, CIII increased significantly in the upper $150 \mathrm{~m}$ and dominated the population while CIV and CV remained dominant at the 2 lower depth strata.

\section{Length vs. carbon regression}

Calanus finmarchicus and C. glacialis (data combined) and $C$. hyperboreus by itself gained a significant amount of carbon between the pre- and early bloom, and the late- and post-bloom periods $(p<0.01)$, while prosome length did not differ significantly $(p>0.05)$. To calculate carbon-specific production rates, the relationship between prosome length of Calanus spp. and carbon content was established from a least-squares

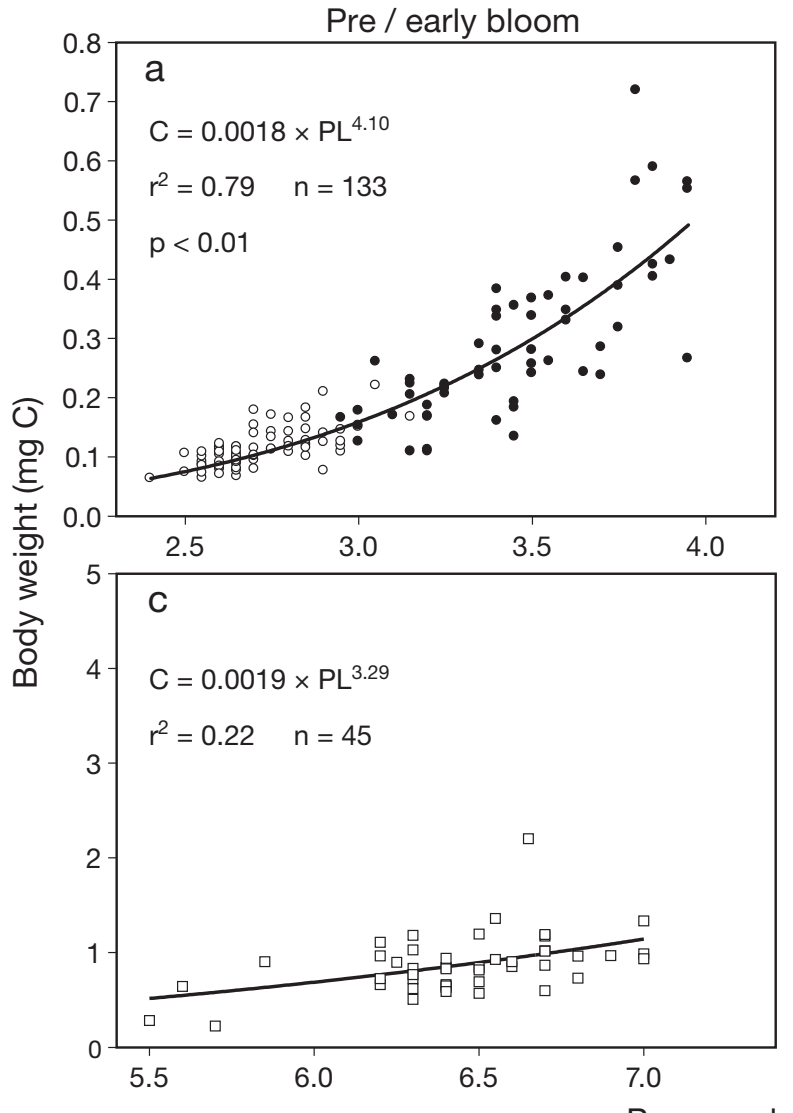

power regression, which found a significant correlation for C. finmarchicus and C. glacialis ( $\mathrm{p}<0.01)$ (Fig. 4). There was no difference between the slopes but a significant difference between the intercepts of the curves describing the 2 bloom periods for $C$. finmarchicus and C. glacialis combined, and also for C. hyperboreus ( $\mathrm{p}<$ 0.01 ), indicating an increased carbon density. It should be noted that for $C$. hyperboreus, this difference does result in a lower carbon weight during late- and postbloom when applied to the smaller development stages.

\section{Egg and pellet carbon}

The slope of the relationship between carbon and fecal pellet volume was not different for the 2 phytoplankton diets ( $p>0.5$ ) (Fig. 5a) and one common slope was calculated. Calanus finmarchicus pellets contained $4.3 \times 10^{-8} \mu \mathrm{g} \mathrm{C} \mu \mathrm{m}^{-3}$ (Fig. 6). The carbon and egg volume relationship for C. finmarchicus and C. glacialis eggs, combined, showed the eggs to contain $11 \times$ $10^{-8} \mu \mathrm{g} \mathrm{C}_{\mu \mathrm{m}^{-3}}$. The nitrogen content of the eggs was $3.13 \times 10^{-8} \mu \mathrm{g} \mathrm{N} \mu \mathrm{m}^{-3}$ (data not shown).

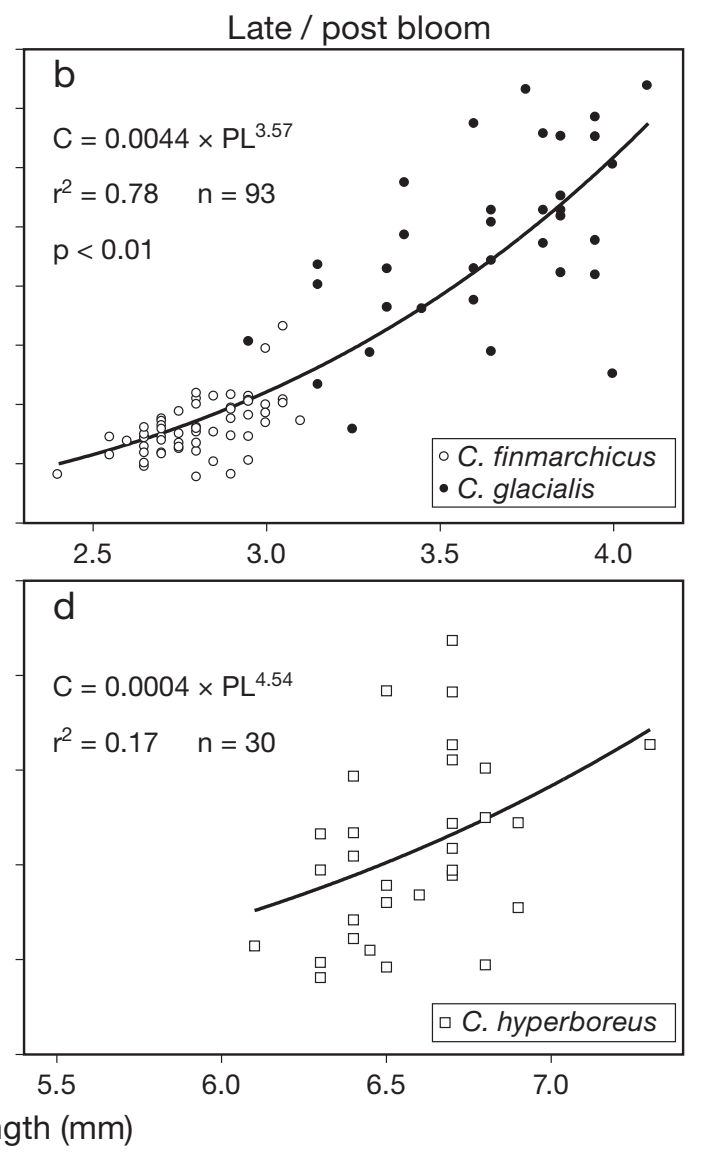

Fig. 4. Calanus finmarchicus, C. glacialis, and C. hyperboreus. Relationship between prosome length (PL) and carbon content for $(\mathrm{a}, \mathrm{b})$ C. finmarchicus and C. glacialis, and $(\mathrm{c}, \mathrm{d})$ C. hyperboreus, in $(\mathrm{a}, \mathrm{c})$ pre- and early bloom, and (b,d) late- and postbloom periods. The p-values are from ANOVA. Note the different scales on the $y$-axes 

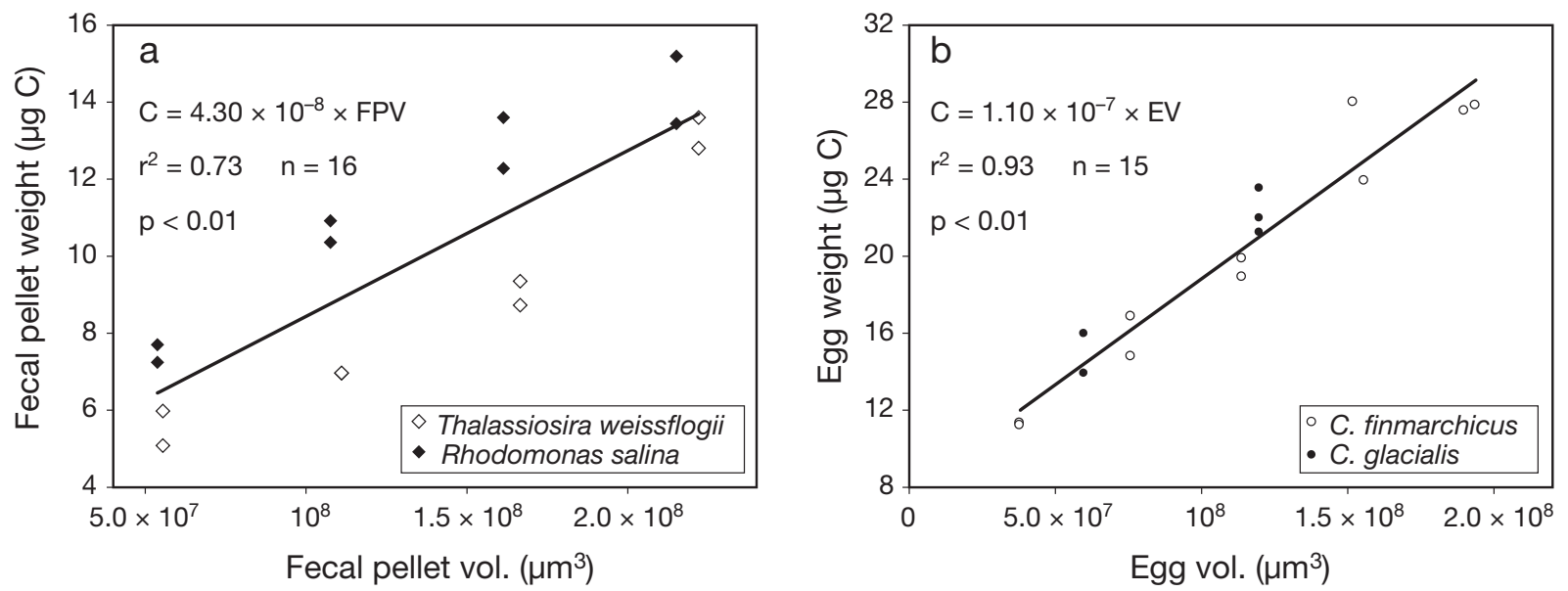

Fig. 5. Calanus finmarchicus and C. glacialis. Relationship between (a) fecal pellet volume (FPV) and fecal pellet carbon weight for C. finmarchicus fed on either Rhodomonas salina or Thalassiosira weissflogii, and (b) egg volume (EV) and egg carbon weight for C. finmarchicus and C. glacialis. The p-values are from ANOVA. Note the different scales on the $y$-axes
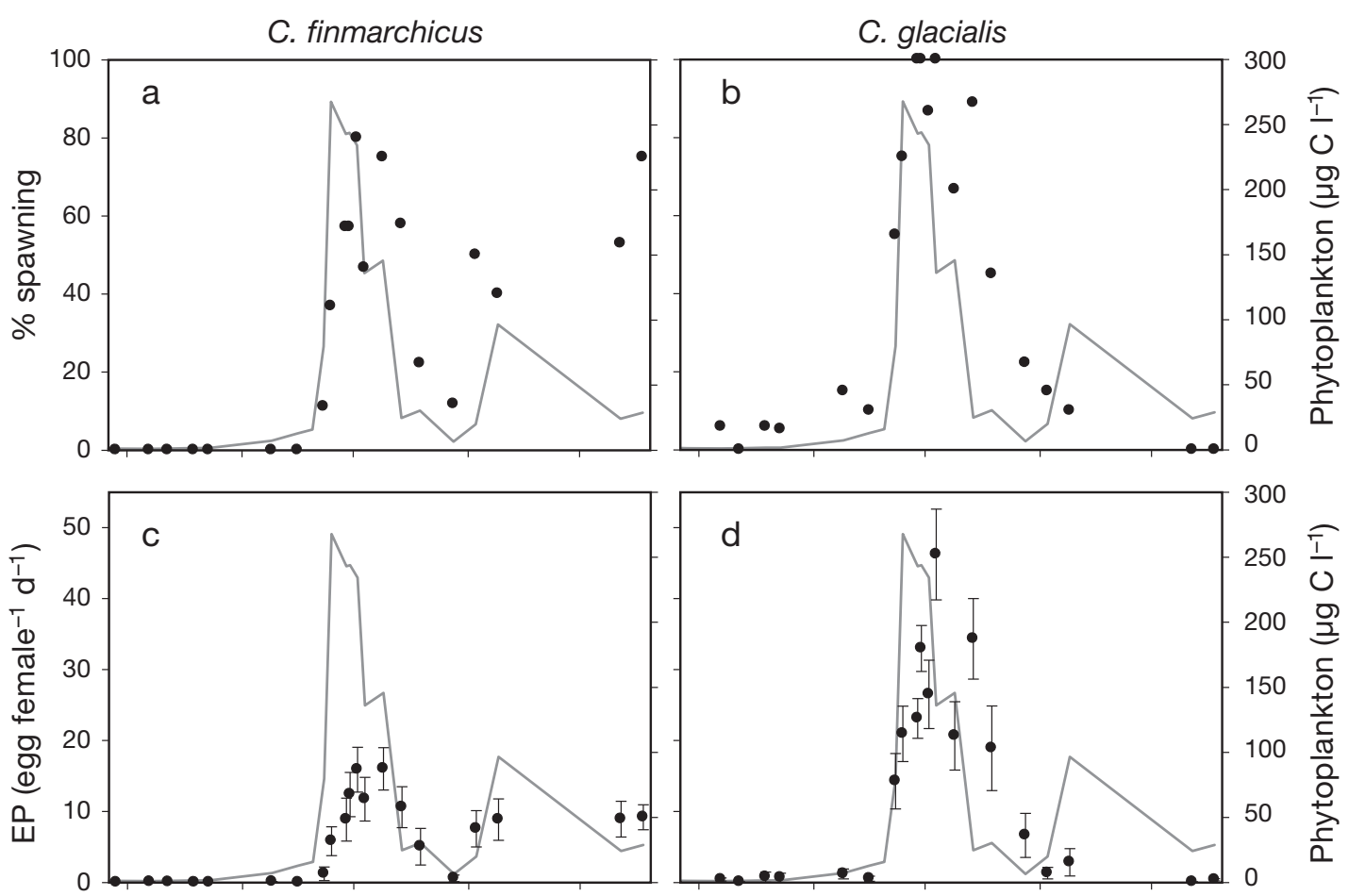

Fig. 6. Calanus finmarchicus and C. glacialis. $(\mathrm{a}, \mathrm{b})$ Percentage of females spawning (when egg production $[\mathrm{EP}]$ female $\left.\mathrm{d}^{-1} \geq 2\right)$, (c,d) EP per female per day, and $(\mathrm{e}, \mathrm{f})$ specific egg production (SEP) in percentage per day. Error bars represent SE. Mean phytoplankton carbon in the upper $100 \mathrm{~m}$ (grey line) is displayed on all graphs
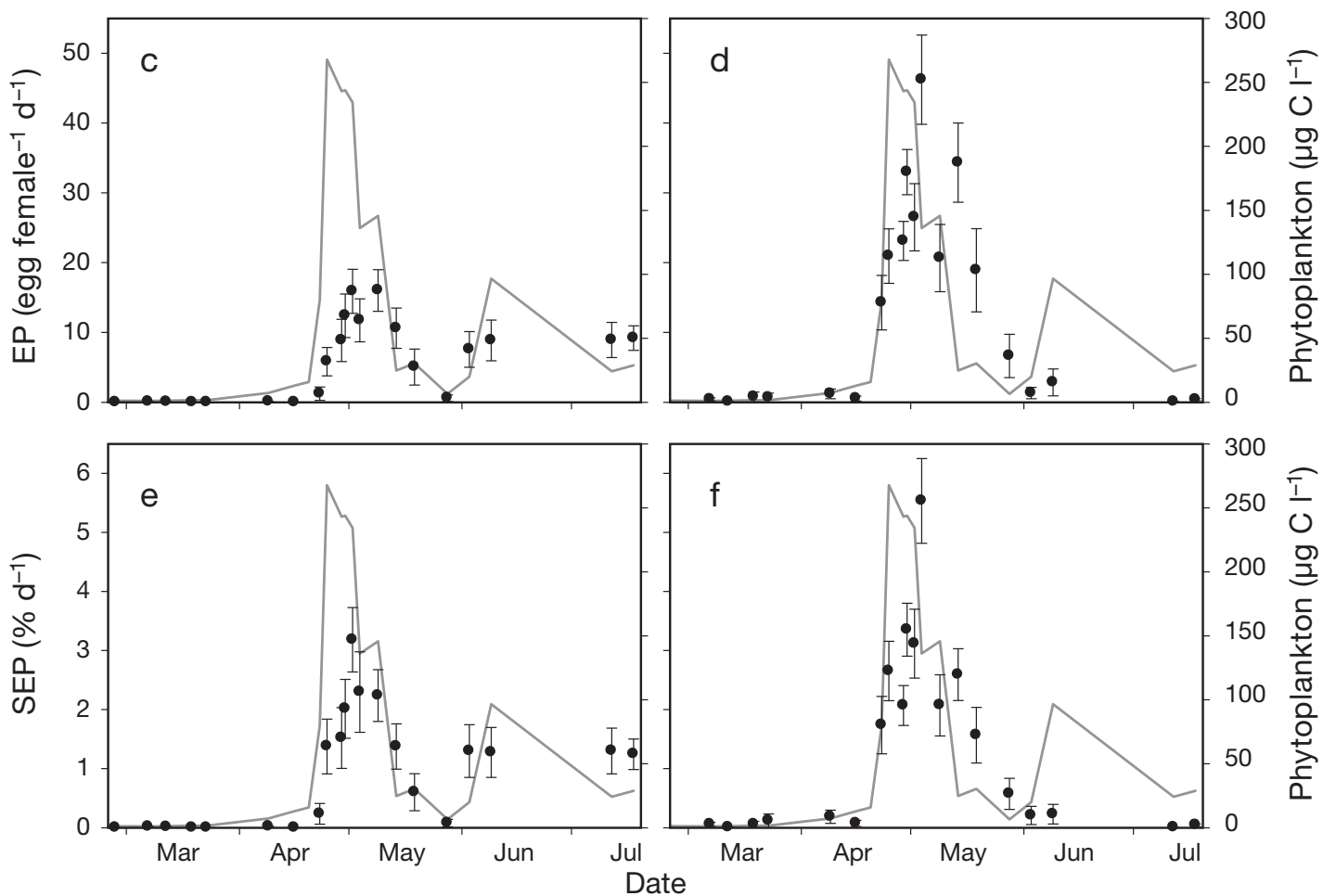


\section{Egg production rate}

EP and percentage of spawning females differed significantly over the season and between Calanus finmarchicus and C. glacialis (Fig. 6). In the pre-bloom period (27 February to 16 April), none (criteria: EP female ${ }^{-1} \mathrm{~d}^{-1} \geq 2$ ) of the $C$. finmarchicus females were spawning (mean EP: 0.03 eggs female ${ }^{-1} \mathrm{~d}^{-1}$ ) compared with an average of $7 \%$ of the $C$. glacialis females with an EP of 0.6 eggs female ${ }^{-1} \mathrm{~d}^{-1}(\mathrm{p}<0.05)$ (Fig. 6a-d). During the bloom period (23 April to 19 May) in the upper $100 \mathrm{~m}\left(>1 \mu \mathrm{g} \mathrm{chl} \mathrm{a} \mathrm{l}^{-1}\right.$ or $\left.30 \mu \mathrm{g} \mathrm{Cl}^{-1}\right)$, spawning percentage and EP increased significantly for C. finmarchicus to an average of $49 \%$ and 9.7 eggs female ${ }^{-1}$ $\mathrm{d}^{-1}$, respectively $(\mathrm{p}<0.01)$, with some females producing up to 41 eggs $\mathrm{d}^{-1}$. For C. glacialis, the spawning percentage and EP increased significantly to an average of $80 \%$ and 26.4 eggs female ${ }^{-1} \mathrm{~d}^{-1}$, respectively ( $\mathrm{p}$

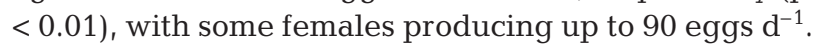
C. glacialis maintained a significantly higher spawning percentage and EP than C. finmarchicus during this period ( $\mathrm{p}<0.05$ ). On 28 May, chl a had decreased to 0.2 $\mu \mathrm{g}^{-1}$ and spawning percentage and EP decreased for both species. The development of a subsurface bloom around 9 June stimulated the spawning percentage and EP of C. finmarchicus to an average of $46 \%$ and 7.0 eggs female ${ }^{-1} \mathrm{~d}^{-1}$ during the post-bloom period ( 28 May to 18 July), while the number of spawning $C$. glacialis decreased significantly to $9 \%$, with an EP of
2.2 eggs female ${ }^{-1} \mathrm{~d}^{-1}$, compared to the bloom period ( $\mathrm{p}$ $<0.05$ ). During the post-bloom period, C. finmarchicus had a significantly higher spawning percentage and EP than C. glacialis $(\mathrm{p}<0.05)$. There were also significant changes in SEP for $C$. finmarchicus between the pre-bloom period compared to the bloom and postbloom periods $(\mathrm{p}<0.01)$, and for C. glacialis between the bloom period compared to the pre- and post-bloom periods ( $\mathrm{p}<0.01)$ (Fig. 6e,f). During the pre-bloom and bloom period, C. glacialis maintained a significantly higher SEP of 0.1 and $2.7 \% \mathrm{~d}^{-1}$ compared to $C$. finmarchicus with 0.01 and $1.7 \% \mathrm{~d}^{-1}$, respectively $(\mathrm{p}<0.05)$. This was opposite to the post-bloom period, during which C. finmarchicus had an SEP of $1.0 \% \mathrm{~d}^{-1}$ compared to $0.2 \% \mathrm{~d}^{-1}$ for C. glacialis $(\mathrm{p}<0.01)$.

\section{Fecal pellet production rate}

FP and SPP for all 3 Calanus species followed the changes in phytoplankton concentration closely (Fig. 7). During the pre-bloom period, C. finmarchicus had an average FP of 2.4 pellets female ${ }^{-1} \mathrm{~d}^{-1}$, which was lower than the 3.2 pellets female ${ }^{-1} \mathrm{~d}^{-1}$ for C. glacialis $(\mathrm{p}<0.01)$ (Fig. $7 \mathrm{a}, \mathrm{b})$. There was no significant difference between the 2 species with respect to SPP $(p>$ 0.05) (Fig. 7d,e). During the bloom period, FP for C. finmarchicus significantly increased to an average of 27.1 pellets female ${ }^{-1} \mathrm{~d}^{-1}$, corresponding to an SPP of

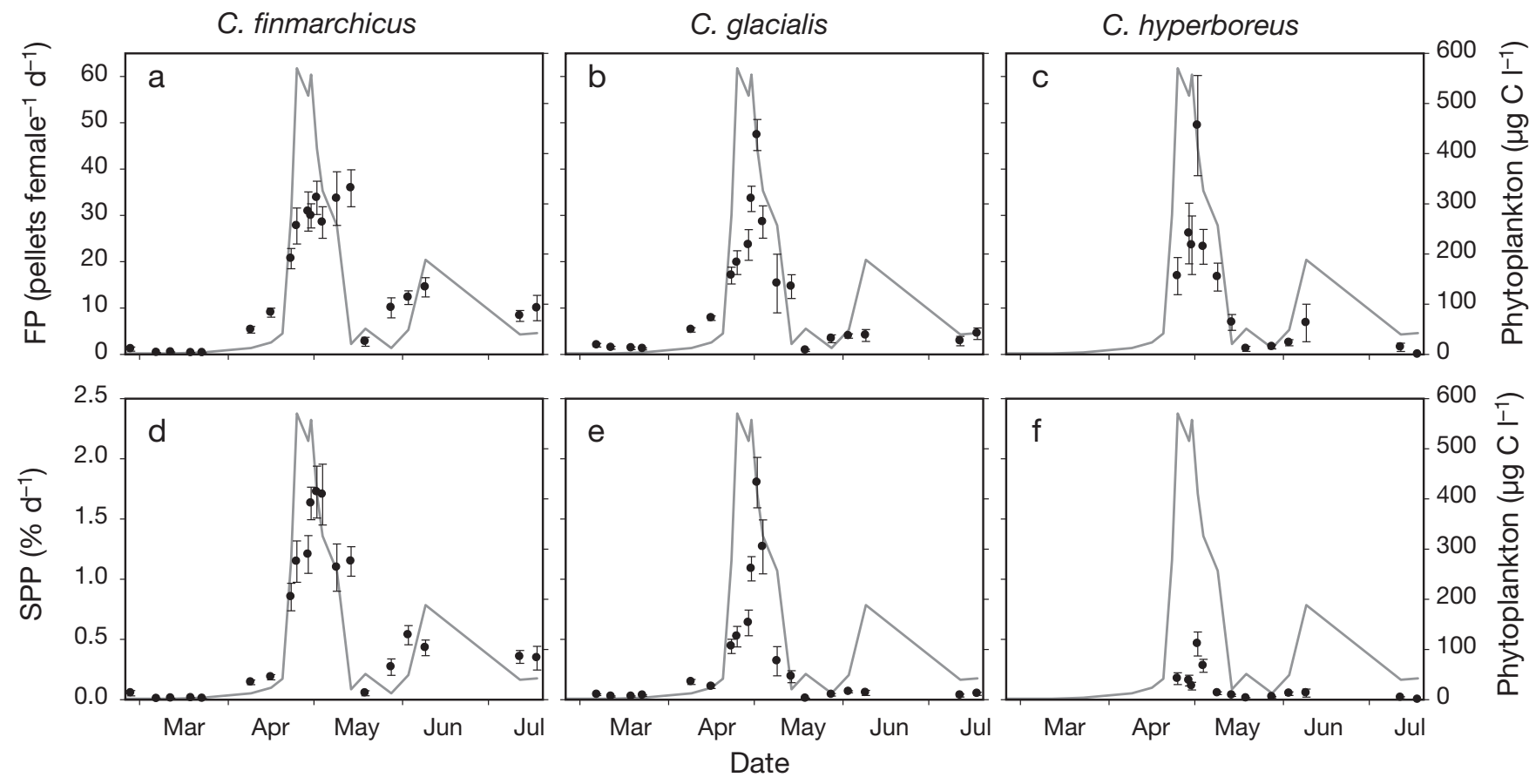

Fig. 7. Calanus finmarchicus, C. glacialis, and C. hyperboreus. (a-c) Fecal pellet production (FP) per female per day and (d-f) specific fecal pellet production (SPP) in percentage per day. Error bars represent SE. Mean phytoplankton carbon in the upper $20 \mathrm{~m}$ (grey line) is displayed on all graphs 
$1.2 \% \mathrm{~d}^{-1}$, while FP for C. glacialis increased significantly to an average of 22.3 pellets female $\mathrm{e}^{-1} \mathrm{~d}^{-1}$, corresponding to an SPP of $0.7 \% \mathrm{~d}^{-1}(\mathrm{p}<0.01)$ (Fig. $\left.7 \mathrm{a}, \mathrm{b}, \mathrm{d}, \mathrm{e}\right)$. $C$. finmarchicus had a significantly higher FP and SPP than C. glacialis $(\mathrm{p}<0.05)$. During post-bloom conditions, FP and SPP decreased significantly to 11.0 pellets female ${ }^{-1} \mathrm{~d}^{-1}$ and $0.4 \% \mathrm{~d}^{-1}$ respectively for C. finmarchicus, and 3.8 pellets female ${ }^{-1} \mathrm{~d}^{-1}$ and $0.1 \% \mathrm{~d}^{-1}$ for C. glacialis $(\mathrm{p}<0.01)$. C. finmarchicus continued to have a significantly higher FP and SPP than C. glacialis $(\mathrm{p}<0.05)$. C. hyperboreus had a significant decrease in pellet production from the bloom to the post-bloom period, with FP going from 20.5 to 2.5 pellets female ${ }^{-1}$ $\mathrm{d}^{-1}$ and SPP going from 0.2 to $0.03 \% \mathrm{~d}^{-1}(\mathrm{p}<0.01)$ (Fig. 7c,f). C. hyperboreus had a significantly lower FP than C. finmarchicus and C. glacialis during the postbloom and than $C$. finmarchicus in the bloom period $(p<0.05)$. SPP was significantly lower compared to both species in both periods $(\mathrm{p}<0.05)$.

SPP of the 3 Calanus species was correlated to chl a in the upper $20 \mathrm{~m}$ (incubation water) of the water column $(p<0.01)$ and could be described by a hyperbolic function $(y=a x /(b+x))$ as suggested by Hansen et al. (1997). A strong correlation was noted between the SPP of C. finmarchicus, C. glacialis, and C. hyperboreus, respectively, and the $10-50 \mu \mathrm{m}$ chl a fraction $\left(\mathrm{r}^{2}=0.49,0.44\right.$, and 0.23 , respectively), suggesting that all 3 species primarily feed on phytoplankton cells larger than $10 \mu \mathrm{m}$.

\section{Carbon, nitrogen, and lipids}

During the bloom, all 3 Calanus species showed significant changes in body weight with respect to carbon and total lipid content (calculated as the sum of TAG, phospholipids, and WE) (Fig. 8a-C). In the pre-bloom period (23 March to 16 April), C. finmarchicus had a mean carbon content of $104 \mu \mathrm{gg}$ female $^{-1}$, which

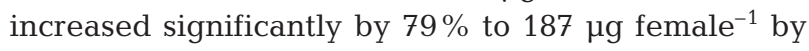
19 May at the transition from bloom to post-bloom period ( $<$ < 0.01) (Fig. 8a). During the same time span, C. glacialis also saw a significant increase in carbon content by $79 \%$ from 256 to $458 \mu \mathrm{g}$ female $^{-1}$ (p < 0.01) (Fig. 8b), and for C. hyperboreus it increased by $249 \%$ from 745 to $2605 \mu \mathrm{g}$ female $^{-1}$ (p < 0.01) (Fig. 8c). On 3 June in the post-bloom period, $C$. finmarchicus and $C$. hyperboreus had decreased in carbon content by $18 \%$ and $45 \%$, respectively, compared to 19 May, while $C$. glacialis had increased by $8 \%$. The nitrogen content of all 3 species also increased during the study period, and the $\mathrm{C}: \mathrm{N}$ ratio was decreasing for $C$. finmarchicus and increasing for C. glacialis and C. hyperboreus (Table 2). For C. finmarchicus, total lipid content also changed from the pre-bloom period to 19 May. While carbon content increased, total lipid content decreased, although not significantly, by $38 \%$ from 63 to $39 \mu \mathrm{g}$ female $^{-1}$ (Fig. 8a). This relationship was not detected for C. glacialis and C. hyperboreus. Total lipid content increased significantly by $184 \%$ from 102 to $290 \mu \mathrm{g}$ female $^{-1}(\mathrm{p}<0.01)$ and by $374 \%$ from 411 to $1946 \mu \mathrm{g}$ female $^{-1}(\mathrm{p}<0.01)$ for C. glacialis and C. hyperboreus, respectively (Fig. 8b,c). When comparing the total lipid content on 19 May with that of 3 June, all 3 species showed a decrease, ranging from $9 \%$ to $24 \%$.

The prosome length of all 3 Calanus species increased, although not significantly, by 0.1 to $0.3 \mathrm{~mm}$ towards the late and post-bloom period (Table 2). The total lipid to carbon ratios (Table 2) do, however, support the different developments for the 3 Calanus species (Fig. 8a-C), which is that C. finmarchicus had a greatly reduced total lipid content in relation to body mass while C. glacialis and especially C. hyperboreus showed a great increase in total lipid content.

TAG content increased exponentially during the phytoplankton bloom for all 3 Calanus species (Fig. 8d-f). C. hyperboreus, however, showed a delay compared to the 2 other species. The TAG content was highest in the late bloom for $C$. finmarchicus and C. glacialis, where it had increased by $8-$ and 15 -fold, respectively, compared to the pre-bloom period (Fig. 8d,e). C. hyperboreus peaked at the end of the bloom with a more than 250-fold increase in TAG (Fig. 8f). In post-bloom conditions, the TAG content of all 3 species had decreased, which coincided with the termination of the phytoplankton bloom. C. glacialis tended to have a higher relative amount of TAG than C. finmarchicus and especially C. hyperboreus in relation to total lipid content (Table 2).

The 3 Calanus species also displayed large increases in phospholipid content (Fig. 8g-i). For C. finmarchicus, the highest value was measured before the bloom but with large variations between samples. When excluding this date $(23 \mathrm{March})$ from the pre-bloom period, C. finmarchicus had doubled its phospholipid content during late-bloom conditions and maintained a constant level throughout the late bloom and postbloom period (Fig. 8g). C. glacialis almost tripled in phospholipids late in the bloom and maintained a lower but constant content thereafter (Fig. 8h). By the end of the bloom, $C$. hyperboreus had increased its phospholipid content 7 -fold (Fig. 8i). The highest ratio of phospholipids to total lipids was mainly found during the bloom period, and C. finmarchicus and C. glacialis generally exhibited higher ratios than C. hyperboreus (Table 2). C. finmarchicus did however display the highest relative amounts of phospholipids, which occurred late and post-bloom.

Between pre- and post-bloom, WE content decreased gradually by $62 \%$ for Calanus finmarchicus 


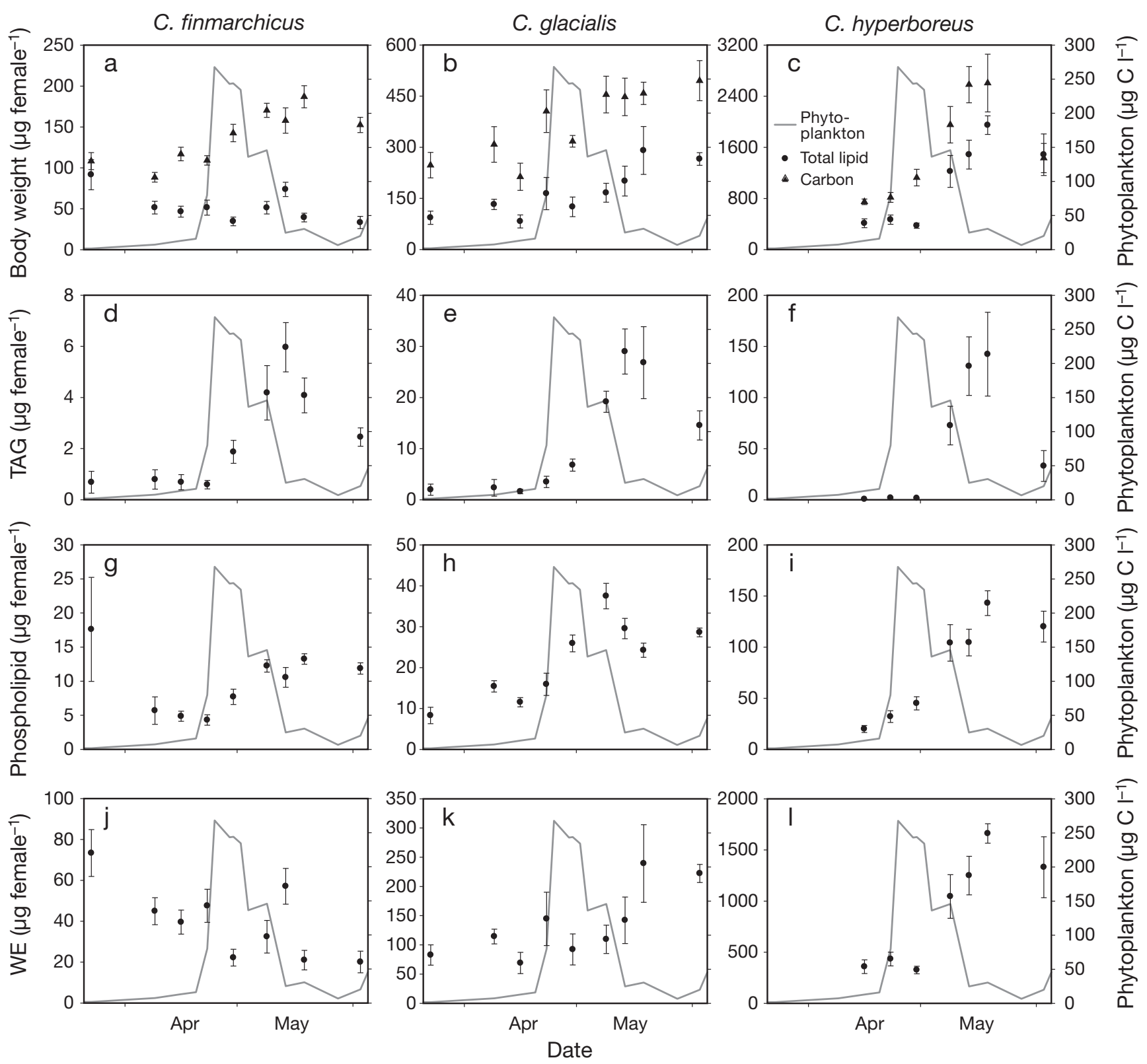

Fig. 8. Calanus finmarchicus, C. glacialis, and C. hyperboreus. (a-c) Body weight per female in terms of carbon and total lipids, $(d-f)$ triacylglycerol (TAG) per female, $(g-i)$ phospholipids per female, and $(j-l)$ wax esters (WE) per female. Error bars represent SE. Mean phytoplankton carbon in the upper $100 \mathrm{~m}$ (grey line) is shown on all graphs. Note the different scales on the $y$-axes

(Fig. 8j). WE content of C. glacialis varied during the pre-bloom and bloom periods and the highest content was found post-bloom (Fig. 8k). Compared to prebloom, C. glacialis increased by $151 \%$. C. hyperboreus maintained a low WE content during the pre- and early bloom, after which it accumulated high amounts of WE (Fig. 81). The highest content was found at the end of the bloom, where it had increased by $364 \%$. The relative amount of WE greatly decreased for C. finmarchicus during the study, and to a smaller extent for C. hyperboreus (Table 2). For C. glacialis, the highest relative amounts were mainly found pre- and postbloom, and there were low ratios during mid-bloom.

The relationship between dry weight and carbon content was established from a linear regression that found a significant correlation for Calanus finmarchicus and the 3 Calanus species combined $(\mathrm{p}<0.01)$ (Table 3). There was a significant difference between the slopes for all 3 species $(\mathrm{p}<0.01)$. C. hyperboreus exhibited the highest carbon to dry weight ratio of 0.71 , compared to C. glacialis (0.60) and C. finmarchicus (0.41). 
Table 2. Calanus finmarchicus, C. glacialis, and C. hyperboreus. Length, carbon, and nitrogen content per adult female and the C:N ratio on specified dates. Total lipid content (TL) per female and in percentage of carbon content (\% C). Triacylglycerol (TAG), phospholipids, and wax ester (WE) are shown as percentage of the total lipid content (\% TL). For carbon content and total lipids per female, sample size is shown in parentheses. Dashed boxes encircle the bloom period. Data are mean $\pm \mathrm{SD}$

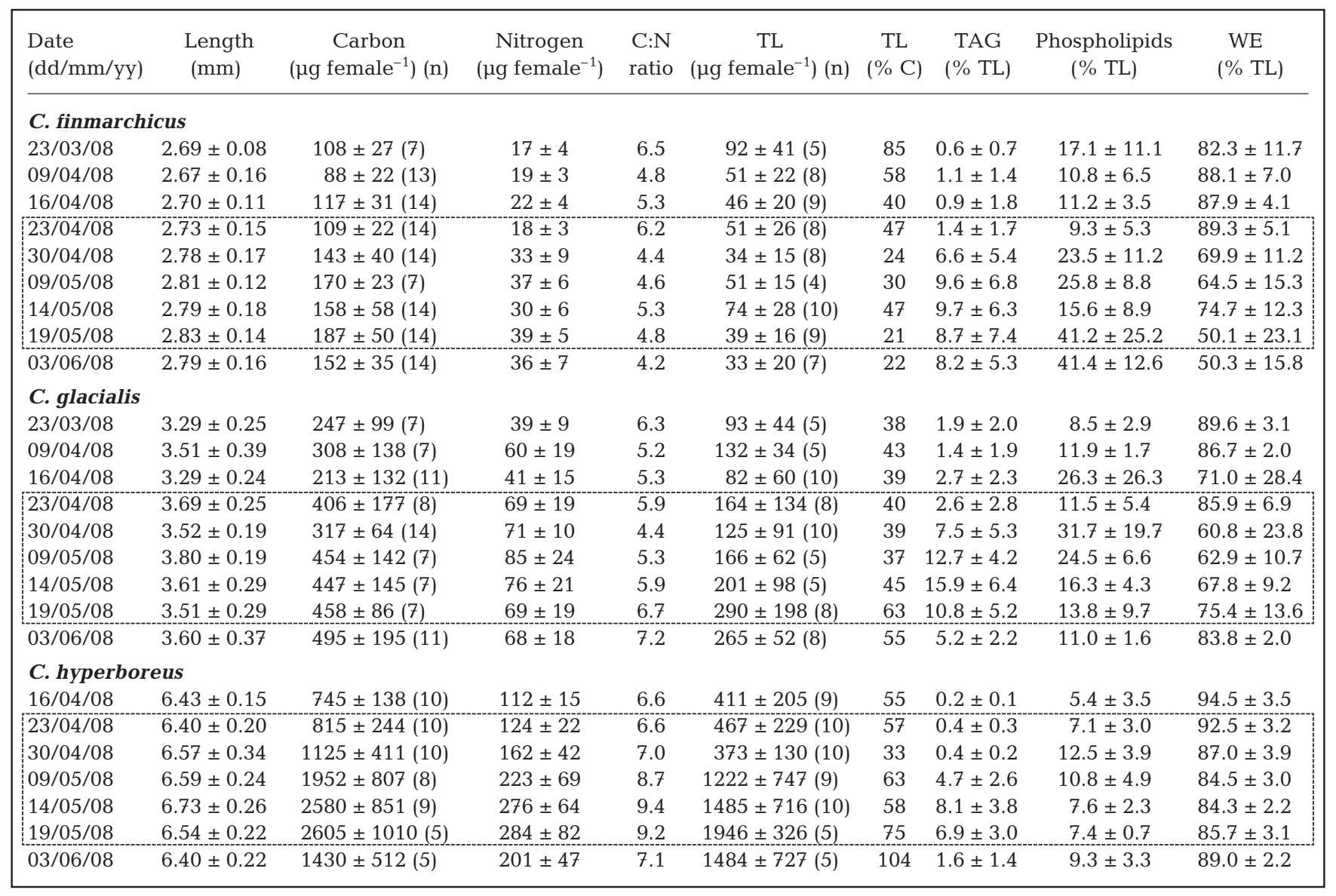

\section{Calanus carbon budgets}

The biomass increase during the bloom period, calculated as the difference in female carbon content (body mass not including SEP) between the pre-bloom and post-bloom (assuming no import/export of individuals to the populations), only shows a $4.4 \%$ biomassincrease difference between Calanus finmarchicus and C. glacialis, while C. hyperboreus was approxi-

Table 3. Calanus finmarchicus, C. glacialis, and C. hyperboreus. Relationship from a linear regression between carbon content and dry weight of adult females. $a$ : slope $\pm \mathrm{SE}, b$ : intercept $\pm \mathrm{SE}$. The $\mathrm{p}$-value is from ANOVA. C. glacialis and C. hyperboreus data were not applicable (na) due to differences in variants

\begin{tabular}{|lccccc|}
\hline Species & $\mathrm{n}$ & $\mathrm{a}$ & $b$ & $\mathrm{R}^{2}$ & $\mathrm{p}$ \\
\hline C. finmarchicus & 390 & $0.4074 \pm 0.0134$ & $0.0066 \pm 0.004$ & 0.71 & $<0.01$ \\
C. glacialis & 327 & $0.6049 \pm 0.0087$ & $-0.0813 \pm 0.0063$ & 0.94 & na \\
C. hyperboreus & 75 & $0.7125 \pm 0.0082$ & $-0.5073 \pm 0.0242$ & 0.99 & na \\
Calanus spp. & 792 & $0.5774 \pm 0.0033$ & $-0.0603 \pm 0.0035$ & 0.97 & $<0.01$ \\
\hline
\end{tabular}

mately $100 \%$ higher (Table 4). The SEP:SPP ratio for $C$. glacialis was generally higher (2 to 11 times) than for $C$. finmarchicus. For both species, this ratio also increased from pre- to post-bloom.

The EP of the populations was higher for Calanus glacialis than for C. finmarchicus during pre-bloom (Table 4). However, EP of $C$. finmarchicus exceeded that of $C$. glacialis during the bloom and in particular during post-bloom. For C. glacialis, $87 \%$ of the EP occurred during the bloom, while for $C$. finmarchicus, $49 \%$ and $51 \%$ occurred during the bloom and post-bloom, respectively, but the females were still reproducing and feeding at the end of the study, so postbloom values may be underestimated. During these 2 periods, the FP of the female population was also higher for $C$. finmarchicus compared to C. glacialis and C. hyperboreus. C. glacialis also exhibited a higher FP during the bloom than C. hyperboreus. 
Table 4. Calanus finmarchicus, C. glacialis, and C. hyperboreus. Biomass increase in percentage (carbon) during the bloom period calculated as the difference between the pre- and post-bloom period. Total (integrated) specific egg production (SEP) and specific fecal pellet production (SPP) in percentage per unit carbon, and total (integrated) biomass, egg production (EP), and fecal pellet production (FP) for the adult female populations in the top $50 \mathrm{~m}$. Brackets contain mean values per day; nd: no data. FP of $C$. hyperboreus was not measured before 25 April, so mean values of the early and late bloom period were used for 16 and 23 April. Note that the durations differ between the pre-bloom (49 d), bloom (33 d), and post-bloom (60 d) period

\begin{tabular}{|c|c|c|c|c|c|c|c|}
\hline Species & Biomass increase (\%) & SEP (\%) & SPP (\%) & SEP:SPP & Biomass (mg C) & EP (mg C) & FP (mg C) \\
\hline \multicolumn{8}{|c|}{ Pre-bloom (27 Feb 27 to $16 \mathrm{Apr}$ ) } \\
\hline C. finmarchicus & nd & $0.3(0.01)$ & $2.6(0.05)$ & 0.1 & 173.9 & $0.6(0.01)$ & $4.5(0.10)$ \\
\hline C. glacialis & nd & $4.2(0.09)$ & $2.9(0.06)$ & 1.4 & 286.1 & $12.0(0.24)$ & $8.3(0.17)$ \\
\hline C. hyperboreus & nd & nd & nd & nd & 5.1 & nd & nd \\
\hline \multicolumn{8}{|c|}{ Bloom (16 Apr to 19 May) } \\
\hline C. finmarchicus & $70.4(2.1)$ & $46.0(1.39)$ & $34.1(1.03)$ & 1.3 & 794.1 & $365.1(11.06)$ & $271.0(8.21)$ \\
\hline C. glacialis & $74.8(2.3)$ & $79.1(2.40)$ & $17.8(0.54)$ & 4.40 & 372.9 & $295.0(8.94)$ & $66.3(2.01)$ \\
\hline C. hyperboreus & $170.7(5.2)$ & nd & $4.3(0.13)$ & nd & 533.4 & nd & $23.1(0.70)$ \\
\hline \multicolumn{8}{|c|}{ Post-bloom (19 May to $18 \mathrm{Jul})$} \\
\hline C. finmarchicus & nd & $65.0(1.08)$ & $21.8(0.36)$ & 3.0 & 582.6 & $378.9(6.32)$ & $127.1(2.12)$ \\
\hline C. glacialis & nd & $17.3(0.29)$ & $2.6(0.04)$ & 6.7 & 186.9 & $32.3(0.54)$ & $4.9(0.08)$ \\
\hline C. hyperboreus & nd & nd & $1.9(0.03)$ & nd & 329.1 & nd & $6.1(0.10)$ \\
\hline
\end{tabular}

\section{DISCUSSION}

\section{Calanus distribution}

During the present study in Disko Bay in 2008, there was an increase in copepod abundance within the surface layer at the onset of the spring bloom, but Calanus hyperboreus was the only species displaying a clear vertical migration through all 5 depth strata. Sampling below $150 \mathrm{~m}$ was not initiated before 9 April so the 2 smaller Calanus species may have left the bottom strata at the time when sampling was initiated. Additionally, the consequence of changing location from the shallower ice station to the deeper monitoring station should be considered. The initial increase in $C$. finmarchicus and C. glacialis abundance may be an artifact due to this, although it was not observed for $C$. hyperboreus. In 1997, C. finmarchicus and C. glacialis had left the lower $100 \mathrm{~m}$ by April (Madsen et al. 2001), so considering that vertical migration that year was delayed by 3 to 4 wk compared to 2008, this could have been the case in the present study. The decrease in $C$. finmarchicus and C. glacialis abundance within the upper $50 \mathrm{~m}$ after the spring bloom, and lack of accumulation near the bottom, points towards other processes like advection or increased predation or age-induced mortality. C. hyperboreus did, however, remain abundant in the top $50 \mathrm{~m}$ and show signs of downward migration at the end of the present study.

The sharp decrease in Calanus spp. abundance in the upper $50 \mathrm{~m}$ during the phytoplankton peak (23 April to 2 May) could be explained by an increase in abundance at the 50 to $100 \mathrm{~m}$ depth strata, similar to reports by Madsen et al. (2008b) for 2005. The investi- gation into the diurnal migration pattern (29 to 30 April) showed downward migration during daytime. Although the midnight sun was present during this period, the irradiance level was substantially lower at night, so diel vertical migration may at least minimize the risk of predation (Dale \& Kaartvedt 2000).

\section{Population development}

Prior to and during the early bloom, the CIII and CIV stages of the 2 smaller Calanus species constituted a large proportion of the community in the upper $100 \mathrm{~m}$. Madsen et al. (2001) also reported the presence of CIII and CIV at this time in 1996, with CI and CII stages occurring in July for C. glacialis and August for C. finmarchicus, in consensus with findings by Ringuette et al. (2002). Rearing experiments by Corkett et al. (1986) showed that development time for $C$. finmarchicus from egg to CIII-CIV would take a minimum of 89 to $106 \mathrm{~d}$, assuming development stages resided in the upper $100 \mathrm{~m}$ with a mean temperature of $-0.7^{\circ} \mathrm{C}$; thus spawning would have had to occur in January. Corkett et al. (1986) reported that all 3 Calanus species displayed similar development times, so spawning of $C$. glacialis would also have occurred at the same time. The experiments of Corkett et al. (1986) were, however, carried out with sufficient food available and at a constant temperature, so development time here could be longer. This indicates that in this study part of the population overwintered as CIII and CIV and molted into CV and possibly CIV later, which could have occurred during May and June. Hence, the occurrence of CIII in the upper $150 \mathrm{~m}$ must have been the product 
of the previous year's spawning. As indicated by the vertical stage distribution pre- and post-bloom, CIV was the primary diapausing stage for copepodites, in agreement with previous studies (e.g. Madsen et al. 2001, Ringuette et al. 2002). It also indicates that $C$. hyperboreus has a 2 yr life cycle, at minimum. The continuous presence of $\mathrm{CV}$ and adult females clearly shows these stages to constitute part of the overwintering population when considering the lower depth strata.

\section{Reproduction and feeding}

Measurements of EP during the present study revealed clear differences in reproductive strategy between Calanus finmarchicus and C. glacialis. The higher pre-bloom EP by C. glacialis than by $C$. finmarchicus (Fig. 6) is in consensus with previous studies (Madsen et al. 2001, 2008b), but output from both species is low compared to other Arctic studies (Smith 1990, Kosobokova \& Hirche 2001). Niehoff et al. (2002) reported that in Disko Bay in 1997, C. glacialis initiated gonad maturation up to $5 \mathrm{wk}$ before $C$. finmarchicus, and by March, $30 \%$ of the females were fully matured as opposed to $10 \%$ for C. finmarchicus. C. glacialis is capable of reproduction fuelled by internal lipid stores (Smith 1990, Hirche \& Kattner 1993) and has a higher EP than C. finmarchicus at low temperatures when food is absent (S. Kjellerup unpubl.). Low chl a concentrations, low SPP (Fig. 7), and a whitish-transparent appearance of the pellets similar to those from laboratory experiments under starved conditions (S. Kjellerup unpubl.) suggests that no feeding took place before the bloom.

The slower response of EP and number of spawning females in Calanus finmarchicus compared to C. glacialis during the initial bloom phase corroborates that C. finmarchicus needs to feed for a period before reproduction starts. Niehoff \& Hirche (1996) and Niehoff (2004) underlined the importance of food for C. finmarchicus in final oocyte maturation. The highest bloom EP attained by $C$. finmarchicus was somewhat lower than other studies in the Arctic (Melle \& Skjoldal 1998, Koski 2007) and at lower latitudes (Gislason 2005, Jónasdóttir et al. 2005). Cannibalism could have caused underestimation of EP rates in the present study, but no broken egg shells were found post-incubation. Moreover, the highest EP reached by C. glacialis attained was within the range of other Arctic studies (Smith 1990, Hirche \& Kwasniewski 1997, Kosobokova \& Hirche 2001, Hirche \& Kosobokova 2003). In 2005, Madsen et al. (2008b) found a maximum EP up to 44 and 48 eggs female ${ }^{-1} \mathrm{~d}^{-1}$ for $C$. finmarchicus and $C$. glacialis, respectively, where the bloom started approx- imately 1 wk earlier compared to 2008. In 1992, 1996, 1997, and 2001, the bloom occurred somewhat later than in 2008, and observations of up to 25 and 35 eggs female ${ }^{-1} \mathrm{~d}^{-1}$ were made for $C$. finmarchicus and $C$. glacialis, respectively (Nielsen \& Hansen 1995, Niehoff et al. 2002, Thor et al. 2005). EP in C. glacialis seems to be rather constant compared to earlier years and other regions in the Arctic, as opposed to C. finmarchicus, which varies substantially.

The 2 smaller Calanus species also displayed different strategies upon termination of the phytoplankton bloom. The chl a concentration decreased around 28 May and resulted in reduced EP and FP, especially for C. finmarchicus. The formation of a subsurface bloom that peaked on 9 June enabled C. finmarchicus to continue feeding and spawning throughout the remaining study period, while C. glacialis did not. In 1997, Levinsen et al. (2000) also reported discontinued feeding by the 2 larger Calanus species during post-bloom. According to Niehoff \& Hirche (2005) and Kosobokova (1998), C. glacialis may also exhibit temperatureinduced dormancy when the temperature exceeds $5^{\circ} \mathrm{C}$. This notion is, however, not supported by other studies carrying out incubations at different temperatures and recording highest EP and FP during a bloom situation at higher temperatures (Hirche \& Kosobokova 2007, S. Kjellerup unpubl.). Nonetheless, C. finmarchicus clearly is more dependent on food to produce eggs and continues to do so when food is available, in line with previous studies (Hirche 1990, Hirche et al. 1997, Niehoff et al. 2002). C. finmarchicus is associated with northern temperate and southern Arctic regions (reviewed by Falk-Petersen et al. 2009) where the spring phytoplankton bloom occurs over a longer period. The continued reproduction of $C$. finmarchicus illustrates adaptations to longer reproduction and feeding periods. C. glacialis and C. hyperboreus, being Arctic species (reviewed by Falk-Petersen et al. 2009), are clearly adapted to shorter, more intense bloom periods by initiating spawning prior to the bloom and terminating feeding and spawning even when food is still available. During post-bloom, protozooplankton may be an important food source (Madsen et al. 2001, Møller et al. 2006). Levinsen et al. (2000) reported positive selection for protozooplankton by all 3 species and found that heterotrophic protists may represent most of the ingested food during post-bloom. Hirche \& Kwasniewski (1997) likewise reported EP fueled by heterotrophic microplankton.

\section{Population production}

The long spawning period during post-bloom conditions made it as important as the bloom in terms of 
reproductive output of the female Calanus finmarchicus population, while the spring bloom was the most important for C. glacialis (Table 4). An estimate of the development time of C. finmarchicus and C. glacialis from egg to their principal diapause stages is, assuming sufficient food and constant temperatures from the beginning of the given period to the end of the study, 100 and $80 \mathrm{~d}$ pre-bloom (mean temperature: $0.4^{\circ} \mathrm{C}$ ), 85 and $70 \mathrm{~d}$ during bloom (mean temperature: $1.3^{\circ} \mathrm{C}$ ), and 71 and $60 \mathrm{~d}$ post-bloom (mean temperature: $2.3^{\circ} \mathrm{C}$ ) (Corkett et al. 1986). Although less than $0.01 \%$ and $3.5 \%$ of the EP occurred pre-bloom C. finmarchicus and C. glacialis, respectively, the progeny based on these early eggs may have the best chances of survival. Varpe et al. (2007) suggested that early eggs have a disproportionately high contribution to population recruitment due to lower predation risk and optimal timing in relation to food availability to fuel development.

\section{Food requirements for reproduction}

The lower SEP:SPP ratio displayed by Calanus finmarchicus (Table 4) suggests higher food dependency to drive reproduction compared to C. glacialis, assuming that the 2 species ingested food of similar quality. In the post-bloom period, C. finmarchicus generally had lower lipid content relative to body size than $C$. glacialis (Table 2 ) (Scott et al. 2000). This may explain the higher food requirement for EP and biomass increase by C. finmarchicus.

\section{Biomass and lipids}

During the phytoplankton bloom, $18 \%$ and $23 \%$ of the carbon increase in Calanus finmarchicus and C. glacialis, respectively, could be explained by the observed increase in prosome length when calculating the mean of the 2 length-carbon regressions presented in the present study. These carbon measurements are, however, included in the regressions, so this should be considered with some reservation. The increase in body length could be due to sampling of different meta-populations - a problem commonly encountered in in situ studies.

In Calanus finmarchicus, the decrease in total lipid content indicates that protein synthesis and not lipid refueling took place. Phospholipids in Calanus spp. are primarily structural lipids associated with membranes but also an important component of egg yolk (Lee 1991), thus indicating a potential increase in the size or number of cells like oocytes and in maturation and EP, as proposed by Ohman \& Runge (1994). Ohman \&
Runge (1994) also found an increase in C. finmarchicus phospholipid content from March to June, and found that an egg contained $47 \mathrm{ng}$ of phospholipids. Clutch sizes typically range between 2 and 90 eggs (Hirche et al. 1997, Gislason 2005, Madsen et al. 2008b). Considering that the mean female phospholipid content was $9.3 \mu \mathrm{g}$ during the main reproductive period (bloom and post-bloom), one clutch (not including immature oocytes) would account for 1 to $45 \%$ of the female phospholipid content and thus a substantial part of the observed increase between pre- and post-bloom.

Approximately $80 \%$ of the nitrogen in Calanus finmarchicus is incorporated into proteins (Mayzaud 1976). The observed increase in nitrogen relative to carbon indicates a switch from lipids to protein synthesis or a utilization of lipids (Hirche 1990, Mayor et al. 2009). Although the total lipid content in females was generally decreasing throughout the present study, some lipid accumulation did occur late in the bloom period. TAG is primarily a dietary lipid accumulated during feeding (but can also be converted from other lipid classes) and converted into WE for long-term storage (Hakanson 1984) or used directly in EP. The FP rate indicated that the late bloom was also the primary feeding period, which corresponded well with the observed gradual TAG and WE build up followed by the subsequent decrease post-bloom. The continuous high EP indicated that the C. finmarchicus female population is capable of refueling its lipid stores and reproducing simultaneously under favorable conditions or that some females prioritize reproduction and others refueling. Decreases in levels of WE and phospholipids during pre-bloom, and TAG and WE post-bloom, was likely the result of gonad maturation (Falk-Petersen et al. 1987, Jónasdóttir 1999) and EP during post-bloom conditions. Protein may also have been utilized, since C. finmarchicus is capable of switching to protein catabolism from lipid catabolism during periods of starvation (Mayzaud 1976).

For Calanus glacialis, most of the carbon increase can be explained by the rising total lipid content. Protein build up may also have occurred judging from the observed increased nitrogen content (Mayzaud 1976). Fluctuations in TAG, WE, and phospholipid content during pre-bloom could have been an artifact due to low sample size in the first 2 samples. Nonetheless, increases occurred as soon as food became available and continued throughout the bloom period. Increased EP could have accounted for a substantial part of the phospholipid increase. Assuming that C. glacialis eggs contain the same amount of phospholipids relative to volume as $C$. finmarchicus eggs, then $C$. glacialis eggs would contain $74 \mathrm{ng}$ of phospholipids (Ohman \& Runge 1994). Clutch sizes typically range between 2 and 90 eggs (Smith 1990, Hirche \& Kosobokova 2003, 
Madsen et al. 2008b) and the mean female phospholipid content was $24.1 \mu \mathrm{g}$ during the main reproductive period (bloom). One clutch (not including immature oocytes) would thus account for 1 to $28 \%$ of the females' phospholipid content, which would explain some of the increase during the bloom period. It also fits well with the observed decrease from late bloom to post-bloom and the continuous lower level thereafter when reproduction was terminated. Niehoff et al. (2002) observed dematuration of the gonads in C. glacialis after reproduction was terminated. If so, oocyte development would also cease and the lack of eggs in the ovary could, due to their higher relative phospholipid content, lower the total phospholipid content of the females.

Post-bloom dynamics in lipid content also suggests that TAG was converted into WE (Hakanson 1984). Considering the discontinuation of EP and subsequent disappearance from the water column at this time, it indicates that females were refueling for the winter diapause. The drop in spawning percentage after 14 May could be the result of older females dematuring their gonads or a sudden increased recruitment from CV. In 1996-1997, substantial molting did not seem to occur at this time (Niehoff et al. 2002). However, continuous molting from CV to adults has been reported in other areas of the Arctic (Melle \& Skjoldal 1998). Recruitment may not have lowered the observed lipid content considering that $\mathrm{CV}$ and adult females do not necessarily differ in WE or total lipids (Scott et al. 2000), but the question is whether it is only the young females that are refueling and if not, does Calanus glacialis have the ability to spawn more than 1 yr? Kosobokova (1999) found $C$. glacialis females to survive for at least 9 mo after the reproductive period and Conover (1988) proposed that C. glacialis may be able to spawn a second time the following year. If second-year females were present during the bloom, they must have been spawning, considering that $100 \%$ of the females present were spawning. The lipid content during post-bloom was, however, somewhat lower compared to findings in Kongsfjorden during August and September (Scott et al. 2000).

For Calanus hyperboreus, the high carbon increase between pre- and post-bloom conditions could not be explained by an increase in prosome length but rather from the total lipid content since lipid is $\sim 80 \%$ carbon (Jónasdóttir 1999, Hygum et al. 2000). This was also indicated by the increasing $\mathrm{C}: \mathrm{N}$ ratio. However, nitrogen content also increased, possibly due to protein buildup (Hirche 1990). The low TAG content observed during pre- and early bloom conditions, during which time females were producing fecal pellets, suggests that feeding may occur for some time before TAG is accumulated. Earlier investigation by Lee (1974) revealed no changes in phospholipid content with the seasons. Since spawning occurs during winter and early spring, and because Niehoff et al. (2002) only observed females with immature gonads at this time in 1996-1997, the phospholipid increase should not originate from EP. Pasternak et al. (2001) did, however, observe $C$. hyperboreus initiating gonad maturation in April near Tromsø, northern Norway, so it is possible that early developing oocytes could account for some of the increase. The increasing nitrogen content suggests some protein buildup but not at a level that would explain a 7 -fold phospholipid increase from membrane formation alone. C. hyperboreus females have been found to contain up to $246 \mu \mathrm{g}$ of phospholipids (Scott et al. 2000), twice as high as our measurements. The reason for this phospholipid increase cannot be explained by the present study results and should be the subject of further research.

The significant WE increase indicates that females were refueling for the winter diapause. Molting from stage CV to adults mainly occurs between November and March (Niehoff et al. 2002), roughly at the same time as spawning (Smith 1990, Hirche \& Niehoff 1996). Hence in the present study, part of the female population possibly consisted of young females which had not spawned and were preparing for the next year. Conover \& Siferd (1993) also proposed that Calanus hyperboreus may be able to spawn a second time the following year. Both carbon and lipid contents were, however, lower on the last sampling date, which suggests some influence by recruitment, sampling of a different meta-population, or an artifact due to lower sample size.

The 3 species displayed very different strategies with respect to biomass increase, lipid accumulation, and lipid usage. The prosome length increase in the 2 smaller Calanus species could point towards size-specific mortality or advection. However, a change in size frequency distribution would still only account for a minor part of the carbon increase. C. finmarchicus clearly invests all its energy into reproduction for as long as possible, judging from its continued reproduction in mid-July. C. glacialis terminated reproduction when the bloom ended, instead accumulating storage lipids likely in preparation for the subsequent diapause. Considering overlapping spawning and molting periods (Smith 1990, Hirche \& Niehoff 1996, Niehoff et al. 2002), late molters may also choose to prioritize refueling and postpone spawning until the next season. This strategy would also ensure higher reproductive success considering the greater reproductive value of early spawned eggs (Varpe et al. 2009). The present study indicates that female $C$. glacialis and $C$. hyperboreus can reproduce in more than $1 \mathrm{yr}$. 


\section{Life cycles and ecological implications}

When comparing the EP of the 2 smaller Calanus species during the phytoplankton bloom with previous years, the reproductive output seems more variable for C. finmarchicus than for C. glacialis. Changes in the timing of the bloom or in the vertical migration do not affect the reproduction of C. glacialis to the same extent as for $C$. finmarchicus. This is probably due to higher dependency on food for oocyte maturation and spawning for $C$. finmarchicus. C. glacialis also expresses a greater reproductive plasticity in its ability to use stored lipids for early spawning, thus maximizing recruitment success through better timing of the first feeding stages to the phytoplankton bloom (Tourangeau \& Runge 1991, Søreide et al. 2006). Reproduction of C. hyperboreus fueled by stored lipids accumulated during the previous feeding season (Conover 1988, Hirche \& Niehoff 1996) also enables it to successfully cope with year-to-year variations (reviewed by FalkPetersen et al. 2009). The 2 larger Calanus species are better adapted to cope with the variability in sea ice cover and bloom conditions partly because of their ability to arrest development, whereas the smaller Atlantic C. finmarchicus is adapted to more predictable temperate waters like the North Sea (Scott et al. 2000). Copepods with longer life cycles are, however, more exposed to predation, favoring species with short life cycles such as $C$. finmarchicus. Pasternak et al. (2001) proposed that the short intense feeding period by $C$. hyperboreus may be a tradeoff between refueling and risk of predation in this multiyear species.

Changes in the timing of the spring phytoplankton due to changes in sea ice cover and/or wind regime has been reported since 1991 in Disko Bay (Hansen et al. 2006). Future changes in the timing will potentially cause a shift in the composition of the Calanus spp. community. The smaller $C$. finmarchicus containing fewer lipids is likely to thrive in a situation with more predictable bloom conditions (Falk-Petersen et al. 2007, Madsen et al. 2008b) and is better capable of exploiting longer periods of available food in its reproduction. The larger lipid-rich C. glacialis and C. hyperboreus, which are adapted to a short intense feeding season, are probably incapable of fully utilizing a prolonged season where food is available, and consequently $C$. finmarchicus would take over in a warmer, less ice-covered future.

Acknowledgments. This study was financed by the National Environmental Research Institute (NERI), Roskilde University (RUC), Carlsberg Foundation, Oticon Foundation, ECOGREEN, MODREC (Contract no. 3304-FVFP-060683), SUNFISH, DSF (Contract no. 2101-07-0080) and the University of Southern Denmark (SDU). We thank S. Jönasdöttir and M.
Holmer for their help and support. Arctic station in Qeqertarsuaq and the scientific leader O. Tervo, University of Copenhagen, provided us with excellent laboratory facilities and logistical support. At sea, RV 'Porsild' and crew, and captain F. Steffensen on RV 'Maya S.' with crew provided a great working platform. Also we greatly acknowledge B. Søborg in her logistical support, P. Christensen and A. Busk Faaborg for their invaluable technical assistance during lipid analysis, and G. K. Bøg for her help during carbon analysis. Furthermore, we thank K. Tönnesson, K. E. Arendt and M. Hjorth for their support during fieldwork.

\section{LITERATURE CITED}

Buch E (2000) A monograph on the physical oceanography of the Greenland waters. Danish Meteorological Institute, Copenhagen

Conover RJ (1988) Comparative life histories in the genera Calanus and Neocalanus in high latitudes of the northern hemisphere. Hydrobiologia 167-168:127-142

Conover RJ, Siferd TD (1993) Dark-season survival strategies of coastal zone zooplankton in the Canadian Arctic. Arctic 46:303-311

Corkett CJ, McLaren IA, Sevigny JM (1986) The rearing of the marine calanoid copepods Calanus finmarchicus (Gunnerus), C. glacialis Jaschinov and C. hyperboreus Kroyer with comments on the equiproportional rule. Syllogeus 58:539-546

Dale T, Kaartvedt S (2000) Diel patterns in stage-specific vertical migration of Calanus finmarchicus in habitats with midnight sun. ICES J Mar Sci 57:1800-1818

> Dünweber M, Swalethorp R, Kjellerup S, Nielsen TG and others (2010) Succession and fate of the spring diatom bloom in Disko Bay, western Greenland. Mar Ecol Prog Ser 419: $11-29$

Falk-Petersen S, Sargent JR, Tande KS (1987) Lipid composition of zooplankton in relation to the sub-arctic food web. Polar Biol 8:115-120

Falk-Petersen S, Pavlov V, Timofeev S, Sargent JR (2007) Climate variability and possible effects on arctic food chains: the role of Calanus. In: Ørbæk JB, Tombre T, Kallenborn R, Hegseth E, Falk-Petersen S, Hoel AH (eds) Arctic alpine ecosystems and people in a changing environment. Springer-Verlag. Berlin, p 147-166

Falk-Petersen S, Mayzaud P, Kattner G, Sargent JR (2009) Lipids and life strategy of Arctic Calanus. Mar Biol Res 5: 18-39

> Folch J, Lees M, Stanley GHS (1957) A simple method for the isolation and purification of total lipides from animal tissues. J Biol Chem 226:497-509

Gislason A (2005) Seasonal and spatial variability in egg production and biomass of Calanus finmarchicus around Iceland. Mar Ecol Prog Ser 286:177-192

Hakanson JL (1984) The long and short term feeding condition in field-caught Calanus pacificus, as determined form the lipid content. Limnol Oceanogr 29:794-804

> Hansen PJ, Bjørnsen PK, Hansen BW (1997) Zooplankton grazing and growth: scaling within the $2-2000-\mu \mathrm{m}$ body size range. Limnol Oceanogr 42:687-704

Hansen BU, Elberling B, Humlum O, Nielsen N (2006) Meteorological trends (1991-2004) at Arctic Station, Central West Greenland $\left(69^{\circ} 15^{\prime} \mathrm{N}\right)$ in a 130 years perspective. Geogr Tidsskr Danish J Geogr 106:45-55

> Heide-Jørgensen MP, Laidre KL, Logsdon ML, Nielsen TG (2007) Springtime coupling between chlorophyll $a$, sea ice and sea surface temperature in Disko Bay, West Greenland. Prog Oceanogr 73:79-95 
Hirche HJ (1990) Egg production of Calanus finmarchicus at low temperature. Mar Biol 106:53-58

Hirche HJ, Kattner G (1993) Egg production and lipid content of Calanus glacialis in spring: indication of a food-dependent and food-independent reproductive mode. Mar Biol 117:615-622

> Hirche HJ, Kosobokova K (2003) Early reproduction and development of dominant calanoid copepods in the sea ice zone of the Barents Sea-need for a change of paradigms? Mar Biol 143:769-781

Hirche HJ, Kosobokova K (2007) Distribution of Calanus finmarchicus in the northern North Atlantic and Arctic Ocean-Expatriation and potential colonization. DeepSea Res II 54:2729-2747

Hirche HJ, Kwasniewski S (1997) Distribution, reproduction and development of Calanus species in the Northeast Water in relation to environmental conditions. J Mar Syst 10:299-317

Hirche HJ, Mumm N (1992) Distribution of dominant copepods in the Nansen Basin, Arctic Ocean, in summer. Deep-Sea Res A 39:S485-S505

Hirche HJ, Niehoff B (1996) Reproduction of the Arctic copepod Calanus hyperboreus in the Greenland Sea-field and laboratory observations. Polar Biol 16:209-219

> Hirche HJ, Meyer U, Niehoff B (1997) Egg production of Calanus finmarchicus: effect of temperature, food and season. Mar Biol 127:609-620

Hygum BH, Rey C, Hansen BW, Tande K (2000) Importance of food quantity to structural growth rate and neutral lipid reserves accumulated in Calanus finmarchicus. Mar Biol 136:1057-1073

Jespersen AM, Christoffersen K (1987) Measurements of chlorophyll-a from phytoplankton using ethanol as extraction solvent. Arch Hydrobiol 109:445-454

> Jónasdóttir SH (1999) Lipid content of Calanus finmarchicus during overwintering in the Faroe-Shetland Channel. Fish Oceanogr 8:61-72

> Jónasdóttir SH, Trung NH, Hansen F, Gärtner S (2005) Egg production and hatching success in the calanoid copepods Calanus helgolandicus and Calanus finmarchicus in the North Sea from March to September 2001. J Plankton Res 27:1239-1259

Kitaysky AS, Golubova EG (2000) Climate change causes contrasting trends in reproductive performance of planktivorous and piscivorous alcids. J Anim Ecol 69:248-262

Koski M (2007) High reproduction of Calanus finmarchicus during a diatom-dominated spring bloom. Mar Biol 151: 1785-1798

Kosobokova KN (1998) New data on the life cycle of Calanus glacialis in the White Sea (based on the seasonal observations of the development of its genital system). Okeanologiya 38:387-396

Kosobokova KN (1999) The reproductive cycle and life history of the Arctic copepod Calanus glacialis in the White Sea. Polar Biol 22:254-263

Kosobokova KN, Hirche HJ (2001) Reproduction of Calanus glacialis in the Laptev Sea, Arctic Ocean. Polar Biol 24: 33-43

> Laidre KL, Heide-Jørgensen MP, Nielsen TG (2007) Role of the bowhead whale as a predator in West Greenland. Mar Ecol Prog Ser 346:285-297

Lee RF (1974) Lipid composition of the copepod Calanus hyperboreus form Arctic Ocean. Changes with depth and season. Mar Biol 26:313-318

Lee RF (1991) Lipoproteins from the hemolymph and ovaries of marine invertebrates. Adv Comp Environ Physiol 7: $187-207$
Lee RF, Hagen W, Kattner G (2006) Lipid storage in marine zooplankton. Mar Ecol Prog Ser 307:273-306

Levinsen H, Turner JT, Nielsen TG, Hansen BW (2000) On the trophic coupling between protists and copepods in arctic marine ecosystems. Mar Ecol Prog Ser 204:65-77

Madsen ML (2005) Lipidklassebestemmelse af den oceaniske calanoide copepod Calanus finmarchicus (Gunnerus) med HPLC-ELSD. MSc thesis, Roskilde University

> Madsen SD, Nielsen TG, Hansen BW (2001) Annual population development and production by Calanus finmarchicus, C. glacialis and C. hyperboreus in Disko Bay, western Greenland. Mar Biol 139:75-93

> Madsen ML, Gaard E, Hansen BW (2008a) Wax-ester mobilization by female Calanus finmarchicus (Gunnerus) during spring ascendance and advection to the Faroe Shelf. ICES J Mar Sci 65:1112-1121

Madsen SJ, Nielsen TG, Tervo OM, Söderkvist J (2008b) Importance of feeding for egg production in Calanus finmarchicus and C. glacialis during the Arctic spring. Mar Ecol Prog Ser 353:177-190

> Mayor DJ, Anderson TR, Pond DW, Irigoien X (2009) Egg production and associated losses of carbon, nitrogen and fatty acids from maternal biomass in Calanus finmarchicus before the spring bloom. J Mar Syst 78:505-510

> Mayzaud P (1976) Respiration and nitrogen excretion of zooplankton. IV. The influence of starvation on the metabolism and the biochemical composition of some species. Mar Biol 37:47-58

> Melle W, Skjoldal HR (1998) Reproduction and development of Calanus finmarchicus, C. glacialis and C. hyperboreus in the Barents Sea. Mar Ecol Prog Ser 169:211-228

Møller EF, Nielsen TG, Richardson K (2006) The zooplankton community in the Greenland Sea: composition and role in carbon turnover. Deep Sea Res I 53:76-93

Niehoff B (2004) The effect of food limitation on gonad development and egg production of the planktonic copepod Calanus finmarchicus. J Exp Mar Biol Ecol 307:237-259

Niehoff B, Hirche HJ (1996) Oogenesis and gonad maturation in the copepod Calanus finmarchicus and the prediction of egg production from preserved samples. Polar Biol 16: $601-612$

Niehoff B, Hirche HJ (2005) Reproduction of Calanus glacialis in the Lurefjord (western Norway): indication for temperature-induced female dormancy. Mar Ecol Prog Ser 285: $107-115$

Niehoff B, Madsen S, Hansen BW, Nielsen TG (2002) Reproductive cycles of three dominant Calanus species in Disko Bay, West Greenland. Mar Biol 140:567-576

Nielsen TG, Hansen B (1995) Plankton community structure and carbon cycling in the western coast of Greenland during and after the sedimentation of a diatom bloom. Mar Ecol Prog Ser 125:239-257

Ohman MD, Runge JA (1994) Sustained fecundity when phytoplankton resourses are in short supply: omnivory by Calanus finmarchicus in the Gulf of St. Lawrence. Limnol Oceanogr 39:21-36

> Pasternak A, Arashkevich E, Tande K, Falkenhaug T (2001) Seasonal changes in feeding, gonad development and lipid stores in Calanus finmarchicus and C. hyperboreus from Malangen, northern Norway. Mar Biol 138:1141-1152

> Planque B, Batten SD (2000) Calanus finmarchicus in the North Atlantic: the year of Calanus in the context of interdecadal change. ICES J Mar Sci 57:1528-1535

> Richardson K, Jónasdóttir SH, Hay SJ, Christoffersen A (1999) Calanus finmarchicus egg production and food availability in the Faroe-Shetland Channel and northern North Sea: October-March. Fish Oceanogr 8:153-162 
Ringuette M, Fortier L, Fortier M, Runge JA and others (2002) Advanced recruitment and accelerated population development in Arctic calanoid copepods of the North Water. Deep-Sea Res II 49:5081-5099

Saito H, Kotani Y (2000) Lipids of four boreal species of calanoid copepods: origin of monoene fats of marine animals at higher trophic levels in the grazing food chain in the subarctic ocean ecosystem. Mar Chem 71:69-82

Scott CL, Kwasniewski S, Falk-Petersen S, Sargent JR (2000) Lipids and life strategies of Calanus finmarchicus, Calanus glacialis and Calanus hyperboreus in late autumn, Kongsfjorden, Svalbard. Polar Biol 23:510-516

Smith SL (1990) Egg production and feeding by copepods prior to the spring bloom of phytoplankton in Fram Strait, Greenland Sea. Mar Biol 106:59-69

Søreide JE, Hop H, Carroll ML, Falk-Petersen S, Hegseth EN (2006) Seasonal food web structures and sympagicpelagic coupling in the European Arctic revealed by stable isotopes and a two-source food web model. Prog

Editorial responsibility: Edward Durbin, Narragansett, Rhode Island, USA
Oceanogr 71:59-87

> Thibault D, Head EJH, Wheeler PA (1999) Mesozooplankton in the Arctic Ocean in summer. Deep-Sea Res I 46:1391-1415

> Thor P, Nielsen TG, Tiselius P, Juul-Pedersen T and others (2005) Post-spring bloom community structure of pelagic copepods in the Disko Bay, Western Greenland. J Plankton Res 27:341-356

Tourangeau S, Runge JA (1991) Reproduction of Calanus glacialis under ice in spring in southeastern Hudson Bay, Canada. Mar Biol 108:227-233

> Varpe Ø, Jørgensen C, Tarling GA, Fiksen Ø (2007) Early is better: seasonal egg fitness and timing of reproduction in a zooplankton life-history model. Oikos 116:1331-1342

Varpe O, Jørgensen C, Tarling GA, Fiksen O (2009) The adaptive value of energy storage and capital breeding in seasonal environments. Oikos 118:363-370

Zhou X, Arthur G (1992) Improved procedures for the determination of lipid phosphorus by malachite green. J Lipid Res 33:1233-1236

Submitted: April 27, 2010; Accepted: January 27, 2011

Proofs received from author(s): April 21, 2011 